\title{
RESPONSABILIDAD DEL ASESOR FISCAL EN EL FRAUDE FISCAL
}

\author{
Erik MARTÍNEZ-ALDAMA CRISTÓBAL \\ GRADUADO EN DERECHO \\ UNIVERSIDAD DE LA RIOJA
}

SumaRIo: I. Introducción. I.I. Concepto y Definición del Asesor Fiscal. I.2. Marco Regulatorio. II. Análisis del sector. III. Responsabilidad tributaria del asesor fiscal. III.I. Como Responsables Solidarios. III.2. Opciones de Actuación del Asesor Fiscal y Alcance de la Responsabilidad. III.3. Dolo, Culpa o Negligencia del Asesor Fiscal. IV. Responsabilidad penal del asesor fiscal. IV.I. Introducción. IV.2. Naturaleza del Delito de Defraudación Tributaria. IV.3. Punibilidad del Fraude de Ley y Negocios Simulados. IV.4. El Asesor Fiscal como Consultor. IV.5. El Asesor como Representante. IV.6. Excusa Absolutoria. IV.7. Prescripción de la Responsabilidad Penal. V. Blanqueo de capitales. V.I. Caracterización y Evolución del Tipo. V.2. Obligaciones para el Asesor Fiscal derivadas de la Normativa de Prevención del Blanqueo de Capitales. V.3. Obligaciones de Información y Deber de Confidencialidad. VI. Conclusiones.

RESUmen: El objetivo del presente trabajo de fin de Grado en Derecho, es establecer el marco de referencia legal en el cual se definen las responsabilidades asociadas al ejercicio de la actividad profesional de los asesores fiscales. Para lo cual comenzaremos con una introducción, en la que abordaremos las problemáticas en cuanto a la definición de asesor fiscal, así como los desafíos que hacen necesaria la implantación, y posterior desarrollo de la figura. Seguidamente, describiremos de una manera somera el sector económico de la asesoría fiscal. A continuación, analizaremos la responsabilidad tributaria del asesor fiscal y la responsabilidad penal del asesor fiscal derivada del delito de defraudación tributaria. Por último, analizaremos la normativa actual de blanqueo de capitales, así como su incidencia en el desarrollo de la profesión del asesor fiscal, haciendo especial hincapié en las dudas, o directamente problemas, que han sido ocasionadas por la nueva regulación sobre la materia, y realizaremos unas conclusiones generales.

Palabras ClaVe: Asesor Fiscal, Autorregulación, Fraude (Fiscal), Colaborador Activo, Blanqueo de Capitales.

ABSTRACT: The general purpose of this Final Project for my Law Degree, is to establish the legal framework of reference in which there are defined all responsibilities associated with the exercise of the profession of tax advisers. For which, we will begin with an introduction in which, we address the issues regarding the definition of tax adviser, and the challenges that cause the implementation, and further development, of that kind of professional activities. Then we describe, in a brief way, the economic sector of tax advisors. We will analyze the tax liability of the tax advisor, and criminal responsibility of tax advisor derived of tax fraud. Finally, we will analyze the current Money Laundering legislation, and its impact on the professional development of tax advisor, with particular emphasis on questions, or problems, that have been directly originated by the new regulation on this question, and will make some general conclusions.

Key Words: Tax Advisor, Self-Regulation, Tax Evasion, Tax Avoidance, Active Partner, Money Laundering. 


\section{Introducción}

\section{I.I. Concepto y Definición del Asesor Fiscal}

El primer objetivo propuesto es intentar definir qué se entiende por asesor fiscal ${ }^{2}$.

- La definición postulada por el art. I del Borrador del Proyecto de Ley de Regulación del Gestor Tributario ${ }^{3}$ lo expresa como sigue:

«El profesional que, con título administrativo expedido al efecto, e inscrito en el Registro Oficial de Gestores Tributarios del Ministerio de Economía y Hacienda, en virtud de contrato celebrado con el interesado viene obligado a efectuar, en favor de este, determinados servicios consistentes en la realización de operaciones lógicas y matemáticas para la elaboración de las declaraciones y autoliquidaciones que el sujeto pasivo deba presentar ante la Hacienda Pública en cumplimiento de sus obligaciones tributarias».

No obstante, este texto nunca llego a promulgarse y, por ello, no fue objeto del desarrollo reglamentario necesario.

- Es por esa razón por la que considero aplicable la definición de asesor fiscal, recogida en el art. 37.e) del RD 939/1986, de 25 de abril, por el que se aprueba el Reglamento General de Inspección de los Tributos (en adelante RGIT) ${ }^{4}$ que postula:

«El deber de los defensores y asesores de guardar secreto de aquellos datos confidenciales de los que hayan tenido conocimiento como consecuencia de la prestación de sus servicios profesionales, así como el deber de los Abogados y Procuradores de observar lo dispuesto en los arts. 437 y 438 LOPJ. Tendrán la consideración de asesores quienes, con arreglo a Derecho, desarrollen una actividad profesional reconocida que tenga por objeto la asistencia jurídica, económica o financiera».

Esta última definición tiene, un mejor encaje en la situación actual del asesor fiscal que destaca por una ausencia de regulación legal estatal, no habiendo Ley o Reglamento que se ocupe de la actividad del asesoramiento fiscal. Sin embargo, no es menos cierto que el concepto de asesor fiscal aparece citado en numerosos textos legales, tales como el art. II2.7 del RD I065/2007, de 27 de julio, por el que se aprueba el Reglamento General de las actuaciones y los procedimientos de gestión e inspección tributaria y de desarrollo de las normas comunes de los procedimientos de aplicación de los tributos o en la Ley de Régimen Jurídico de las Administraciones Públicas y del Procedimiento Administrativo Común ( en adelante LRJPAC) (art. 85.2).

Además, resulta esencial resaltar la aparición de Códigos Deontológicos del Asesor Fiscal, los cuales han venido unidos al aumento de Asociaciones de Asesores Fiscales (vgr. el Código Deontológico de la Asociación Española de Asesores Financieros y Tributarios -

\footnotetext{
${ }^{1}$ Destacar que en algunas notas al pie de página me ha resultado imposible precisar aspectos como el número de página concreta por tratarse de versiones de los artículos en formato electrónico que carecen de estos datos.

${ }^{2}$ Diccionario de la lengua española, RALE. Edic. 23a , octubre-2or4: asesor, ra. (Del lat. assessor, -ōris, der. de assidēre 'asistir, ayudar'). I. adj. Que asesora. U. t. c. s. // 2. adj. Dicho de un letrado: Que, por razón de oficio, debe aconsejar o ilustrar con su dictamen a un juez lego. U. m. c. s.

3 Cfr. Martinez-Carrasco Pignatelli, J.M El asesor fiscal como sujeto infractor $y$ responsable, Cuadernos Fiscales Madrid Capitulo I.

${ }^{4}$ Versión vigente hasta 2008
} 
AEAFT-5 $^{5}$ o, el de los Asesores de la Comunidad Valenciana). Empero, no solo encontraremos ejemplos de Códigos Deontológicos en el ámbito público, sino que también existen bastantes empresas que, para desarrollar mejor la práctica de la asesoría fiscal, se dotan de un Código Ético ${ }^{6}$ que regule su actuación.

La figura del asesor fiscal es relativamente nueva en nuestro ordenamiento jurídico. Tomando como referencia los estudios doctrinales acerca de la existencia y funciones de esta figura en bases de datos jurídicas de reconocido prestigio, como puede ser La Ley ${ }^{7}$, nos encontramos con que, aproximadamente un $40 \%$ de los artículos doctrinales sobre el asesor fiscal que aparecen en esta base son del período que comprende 2008-2014; aproximadamente un 37\% de la etapa que va de 2008-2003 (cuando se promulgó la nueva Ley General Tributaria de 2003 ( en adelante LGT)) y un $23 \%$ en la etapa anterior, con una preeminencia de artículos publicados en la materia en los años 200I, I999 y I998 8 .

Todo ello surge a raíz del citado RGIT, que en su art. $25^{9}$, vigente a partir de ○6/1986, decía: «Los sujetos pasivos y demás obligados tributarios podrán intervenir en las actuaciones inspectoras asistidos por un asesor, quien Podrá aconsejar en todo momento a su cliente, y cuyas manifestaciones en presencia del obligado tributario, se considerarán formuladas por éste si no se opone a ellas de inmediato» ${ }^{10}$.

Sin embargo, y pese a estos precedentes, en realidad articulados por textos que establecen un intento de autorregulación, nos encontramos con la paradoja de la no obligatoriedad de colegiación o pertenencia asociativa como requisito sine qua non para desarrollar la citada actividad, como tampoco lo es formar parte de una asociación, por la cual la eficacia de estos códigos deontológicos, muchas veces de alcance claramente regional, se ve seriamente cuestionada.

Es sorprendente que, dada la importancia creciente de esta profesión, y el contexto cada vez más complejo del campo tributario, vgr., en el caso de personas jurídicas asentadas en un ámbito internacional con distintas regulaciones vigentes según los territorios, no tengamos una regulación armonizada; no ya a nivel comunitario (por las más que evidentes dificultades que presenta dicha labor en una materia de corte multidisciplinar, y que excede en algunos aspectos del ámbito competencial de la Unión

5 La AEAFT se creó en I992 para defender y mejorar del desarrollo de la profesión de asesor financiero y tributario con la voluntad de colaborar y participar activamente con los contribuyentes, para que estos puedan distinguir a un profesional del asesoramiento de aquellos que no lo son, y para servir como cauce en las relaciones con la Administración Tributaria. Sus principales objetivos se centran en promover la formación e información en el ámbito profesional del asesoramiento, ayudar al desarrollo normativo, favorecer el intercambio de experiencias entre profesionales y velar para que la profesión se ofrezca con las garantías suficientes de cualidad y competencia. (http://www.asesores.org/seccion/2I/La-Asociacion/)

${ }^{6}$ Puede consultarse: Asesoría Cedrán y Muñoz http://www.cymasesores.es/QUIENES-SOMOS/CodigoEtico/, Acazador http://www.acazador.es/codigo-deontologico-del-asesor-fiscal.htm entre otros.

${ }^{7}$ Búsqueda Asesor Fiscal restringiendo a artículos doctrinales Penales, Fiscales y Procesales.

${ }^{8}$ Vid por ejemplo Banacloche Perez, J.: «Los derechos del Contribuyente» Rev. Impuestos, Ref. D-IO2, Tomo 2-I999 págs. 34-49, LA LEY Madrid. Analiza los requisitos que debían cumplir los asesores fiscales a la luz del art. 25 del RGIT.

${ }^{9}$ Hoy derogado por el RD 1065/2007, de 27 de julio, por el que se aprueba el Reglamento general de las actuaciones y los procedimientos de gestión e inspección tributaria.

1o Señalar que la parte de «cuyas manifestaciones en presencia del obligado tributario, se considerarán formuladas por éste si no se opone a ellas de inmediato» fue anulada por el Tribunal Supremo en I993. 
Europea ( en adelante UE) ${ }^{\mathrm{II}}$, al menos y como mínimo, a nivel estatal, para así lograr, un mayor grado de seguridad jurídica, prevención de la indefensión del obligado tributario, un menor grado de elusión fiscal y, en definitiva, una mejor gestión de los ingresos públicos tributarios tanto desde el punto de vista del sujeto activo como del sujeto pasivo de toda obligación tributaria.

No podemos obviar la enorme complejidad que aportan al ordenamiento tributario los sucesivos y frecuentes cambios legislativos de las normas tributarias: por ejemplo los múltiples cambios que ha sufrido la regulación del Impuesto de la Renta de las Personas Fiscas ( en adelante IRPF) ${ }^{\mathrm{I} 2}$, en este contexto de constante cambio, es claro que se necesita el asesoramiento de un experto, no ya para cumplir las obligaciones tributarias de una manera correcta y adecuada a los intereses del cliente, sino para poder conocer la norma tributaria vigente y los cambios que cada año, afectan al sujeto pasivo.

Por último, también aporta complejidad en la materia tributaria, la retroactividad de las normas tributarias que, si bien no es objeto de este trabajo, si hay que mencionar ya que el art. I0.2 LGT abre la posibilidad a la retroactividad de la norma tributaria, bien que sujeta a unos límites como puede ser el art. 9.3 de la Constitución Española (en adelante CE) ${ }^{13}$

\section{I.2. Marco Regulatorio}

Es conveniente hacer un breve recorrido histórico acerca de la figura del asesor fiscal y las circunstancias que motivan, no solo su aparición sino su progresiva popularización entre las personas físicas y, por supuesto, entre las personas jurídicas, sobre todo de corte empresarial o con un gran patrimonio.

En I964 entró en vigor la Ley General Tributaria de I963, a consecuencia de la Reforma Tributaria impulsada por Navarro Rubio que, además, estableció el Plan de Estabilización y fue directamente responsable de la Ley de Tasas y Exacciones Parafiscales, que inicia la «privatización» ${ }^{\text {I4 }}$ de la gestión tributaria, en la cual el contribuyente va a ir adquiriendo un mayor papel a la hora de gestionar sus tributos.

Este proceso continúa a raíz de la reforma del Ministro F. Fernández Ordoñez de I977 (Ley 50/1977, para la reforma fiscal), que marca un punto de inflexión para pasar, de una antigua Administración muy desligada del contribuyente, a una nueva Administración

\footnotetext{
${ }^{\text {II }}$ Observamos lo anterior en el siguiente precedente: «Los debates mantenidos durante la evaluación recíproca pusieron también al descubierto problemas relacionados con los requisitos de forma jurídica (por ejemplo, restricciones sobre las formas jurídicas que pueden adoptar los operadores que inician determinadas actividades, como puede ser la prohibición para quienes ejercen un oficio manual de constituir una sociedad de capital) y los requisitos en materia de propiedad del capital (por ejemplo, la obligación de poseer cualificaciones específicas a fin de adquirir participaciones en el capital de sociedades que prestan determinados servicios, como puede ser la obligación de ser un asesor fiscal cualificado para adquirir capital en una sociedad que ofrece servicios de asesoramiento fiscal)». COMUNICACIÓN DE LA COMISIÓN AL PARLAMENTO EUROPEO, AL CONSEJO, AL COMITÉ ECONÓMICO Y SOCIAL EUROPEO Y AL COMITÉ DE LAS REGIONES: Hacia un mejor funcionamiento del mercado único de servicios, partiendo de los resultados del proceso de evaluación recíproca de la Directiva de servicios. Bruselas, 27.I.20II. COM (20II).

${ }^{12}$ La Ley 35/2006 de 28 de noviembre del Impuesto Sobre la Renta de las Personas Físicas y modificación parcial de las leyes de los Impuestos sobre Sociedades, sobre la Renta de no Residentes y sobre el Patrimonio redacc.Ley 26/20I4 de 27 de noviembre.

${ }^{13}$ Analizado entre otras por la STC I26/1987.

${ }^{14}$ Cfr. SÁnchez-Pedroche, J. A. Responsabilidad penal, civil $y$ administrativa del asesor fiscal. Editorial Centro de Estudios Financieros Madrid. Pag.ı2
} 
potenciada, mucho más eficiente a la hora de gestionar, liquidar y recaudar los distintos tributos, más cercana al contribuyente, pero imponiéndole múltiples obligaciones colaborativas, en aras de una mejor gestión y recaudación tributaria ${ }^{\mathrm{I}}$.

Esta Administración reforzada, hay que enmarcarla dentro de un contexto, muy complejo desde el punto de vista de la regulación tributaria.

Vamos a encontrar una miríada de disposiciones tributarias, que ayudan a crear una autentica maraña de obligaciones tributarias, difícilmente comprensibles y asimilables, no ya por el contribuyente medio, sino por una empresa medianamente informada. De hecho, acorde con la jurisprudencia, al ciudadano medio no cabe exigírsele el deber de conocer todos los entresijos del ordenamiento jurídico, incluso en ciertas ocasiones nos hallaremos ante una causa de exclusión de la culpabilidad, como sucederá en el caso de que se haga una interpretación razonada y razonable acerca de la aplicación de una norma tributaria, aunque tal interpretación difiera de la efectuada por la Agencia Tributaria ( en adelante AEAT), como ha señalado, entre otras, la STSJ Cataluña de 5-2-1992 ${ }^{16}$.

Desde luego, uno de los elementos que más complejidad aporta al estudio y cumplimiento de las obligaciones tributarias del contribuyente es la llamada presión fiscal directa y presión fiscal indirecta ${ }^{\text {T7 }}$. La presión fiscal directa la forma el total de impuestos (ya sean directos o indirectos, como el Impuesto sobre el Valor Añadido) soportados por el obligado tributario, de hecho, podemos definir la presión fiscal sobre los ciudadanos de un Estado como «La presión fiscal viene definida por el total de impuestos (directos e indirectos) que recauda el sector público en un país en relación con la actividad económica anual del mismo $(P I B) . \quad{ }^{18}$.La llamada presión fiscal indirecta, también conocida como costes de cumplimiento, que se basa en lo que le cuesta al obligado tributario cumplir sus obligaciones tributarias, además de la cuota que debe ingresar como consecuencia de los distintos impuestos. Estos costes de cumplimiento pueden ser en forma de dinero ( lo que le cuesta al contribuyente un asesor fiscal), en forma de tiempo utilizado en confeccionar por ejemplo la autoliquidación tributaria o de tipo psicológico, si tenemos en cuenta la ansiedad que puede producirle al contribuyente no saber si ha errado a la hora de cumplir una obligación determinada.

\footnotetext{
${ }^{15}$ Asociación Española de Asesores Fiscales http://www.asesores.org/noticia/94/migracion/CodigoDeontologico-Todas-las-Paginas.html

${ }^{16}$ La STSJ de Cataluña, 5-2-1992, Rec. I2322/1996 dice: «Ahora bien, y desde una faceta subjetiva, no cabe negar que una diferencia de criterio razonable y razonada respecto de la interpretación de las normas tributarias, a menudo ambiguas y frecuentemente complejas, puede ser causa de exclusión de la culpabilidad, y así lo ha entendido el Tribunal Supremo en sentencia de 2-7-I970, y 2-II-I987, entre otras».
}

Siguiendo el tenor literal de la referida Sentencia de 23-II-I987, «el principio en virtud del cual la ignorancia de las leyes no excusa de su cumplimiento (art. 6.I CC) ha de ser matizado, en el ámbito de la potestad sancionadora mediante las circunstancias subjetivas y objetivas concurrentes, y por ello, determinantes de la actuación o inactividad del inculpado» ya que según apunta más adelante «al ciudadano común que no tiene el deber de conocer los complejos entresijos del ordenamiento jurídico cada día más frondoso, no cabe exigirle el conocimiento de unos saberes con características exotéricas y desprovistas de exactitud; ello elimina la malicia o dolo en su denominación tradicional y por lo tanto excluye culpabilidad».

${ }^{17}$ Autor: Área de Sociología Tributaria. Instituto de Estudios Fiscales: El Impacto de la reforma del IRPF en la presión fiscal indirecta (Los costes de cumplimiento en el IRPF 1998 y 1999), DOC. n 25/200I, Madrid, págs. I6 y SS.

${ }^{18}$ La Presión Fiscal, Informes del Seminario de Economía Critica Taifa http://informes.seminaritaifa.org/lapresion-fiscal/ 
Unido a ello, nos encontramos con una multitud de obligaciones formales ${ }^{\mathrm{r}}$, que dificultan aún más, la correcta comprensión del sistema impositivo español para el conjunto de la ciudadanía, como ha enunciado, entre otros TIPKE ${ }^{2 \mathrm{2 \tau}}$

Es evidente que la Administración ha ido ampliando los supuestos de autoliquidación, hasta convertir el procedimiento de liquidación en una excepción y, si bien es cierto que se han hecho progresos para facilitar estas tareas a los obligados tributarios, no lo es menos que no ha logrado hacer accesibles, en muchos casos, las obligaciones tributarias (materiales y formales) de los contribuyentes, especialmente los de capacidad económica media-alta.

Por tanto, ya desde las reformas de referencia, se hizo necesaria la potenciación de la figura de un experto en la materia fiscal que asesorara al cliente, e incluso lo representara, en el cumplimiento de sus obligaciones tributarias, figura que se plasma en el concepto de asesor fiscal.

\section{Análisis del sector}

Analicemos la situación en la que se halla el sector de las Actividades de Contabilidad, Teneduría de Libros, Auditoría y Asesoría Fiscal (Código Nacional de Actividades Económicas 6920), en el que se enmarca la Asesoría Fiscal, para poder hacernos una idea del volumen de negocio y de las perspectivas a corto-medio plazo del sector (a largo plazo sería más complejo ya que nos encontramos en un sector del ordenamiento jurídico muy volátil y mutable por lo cual las circunstancias pueden variar mucho en un horizonte medio de, por ejemplo, 3 años).

Acorde con el DIRCE ${ }^{22}$, en el año 20I4 nos encontramos con 6r.222 empresas que se dedican a la actividad de Contabilidad, Teneduría de Libros, Auditoria y Asesoría Fiscal.

En el año 2012 el número de empresas era de 57.052, lo que supone un incremento del $7,3 \%$ en dos ejercicios coincidentes con el cenit de la mayor crisis económica de los últimos años en España

Existe un predominio claro de que empresas que carecen de asalariados o, con un máximo de i a 2 asalariados. Este hecho, unido al tipo societario predominante de las Sociedades Limitadas y el de las Personas Físicas, refleja la atomización del sector y el autoempleo.

Vemos, por tanto que se trata de un sector muy disgregado, con un gran número de participantes en el mercado, con unas necesidades de inversión mínimas que, según la

\footnotetext{
${ }^{19}$ Definidas en el art. 29 de la LGT/2003: «Son obligaciones tributarias formales las que, sin tener carácter pecuniario, son impuestas por la normativa tributaria o aduanera a los obligados tributarios, deudores o no del tributo, y cuyo cumplimiento está relacionado con el desarrollo de actuaciones o procedimientos tributarios o aduaneros».

${ }^{20}$ Tipke, K.: Moral Tributaria del Estado $y$ de los contribuyentes, traducción de P.M. Herrera Molina, Marcial Pons, Madrid-2002, pág. 85 .

${ }^{21}$ «Pero desde los años setenta y ochenta son más frecuentes las manifestaciones de magistrados, abogados y profesores que designan el Derecho Tributario vigente como 'caos', 'jungla' e incluso 'perversión'. En este caos las personas con elevados ingresos pueden permitirse un caro asesoramiento fiscal y reducir así legalmente el importe de sus impuestos. Las personas con ingresos reducidos no tienen esa posibilidad. Estos últimos pagan un 'impuesto sobre los tontos'».

${ }^{22}$ Directorio Central de Empresas, Instituto Nacional de Estadística.
} 
regulación vigente, prácticamente no existen barreras jurídicas de entrada, ayudan a que este sector sea bastante atractivo a la hora de emprender una actividad empresarial individual.

Por otra parte, el desarrollo económico y empresarial de esta actividad no está evolucionando de la misma manera que la complejidad del marco tributario en el cual se desarrolla.

\section{Responsabilidad tributaria del asesor fiscal}

\section{III.I. Como Responsables Solidarios}

Para analizar la responsabilidad tributaria del asesor fiscal, resulta imprescindible partir del art. 42.I.a) LGT/2003, que va a considerar responsables solidarios a los que colaboren activamente, o sean causantes de una infracción tributaria además, van a ser también responsables solidarios en la sanción impuesta, lo que distingue a este punto de otras tipologías de responsabilidad tributaria.

Hay que destacar que la solidaridad en el ámbito tributario presenta una diferencia muy importante con la subsidiariedad tributaria (que además es la regla general acorde al art. 4I.2), consistente en el hecho de que, mientras en la obligación subsidiaria la Administración, para dirigirse contra el responsable subsidiario, ha de declarar fallido al deudor principal y a sus responsables solidarios; en la solidaridad no, es decir, la Administración puede dirigirse contra el principal o contra los responsables solidarios, indistintamente y por el todo bien que luego puede jugar el acción de repetición, muy vinculado con la doctrina del enriquecimiento injusto).

La responsabilidad solidaria del art. 4I.2 ${ }^{\mathrm{a}}$ ) va a exigir que se cumplan estos requisitos ${ }^{23}$ :

- Es necesario que el sujeto pasivo (o sustituto, en este estudio vamos a hablar del sujeto pasivo refiriéndonos a ambos conceptos, bien que presentan diferencias), realice el hecho imponible o el presupuesto requerido para algunas instituciones, como la retención a cuenta o la sustitución, para que nazca la obligación tributaria: sin obligación tributaria este precepto deviene inaplicable.

- Es necesario que el sujeto pasivo cometa una infracción tributaria.

- Es necesario que el responsable solidario cause o colabore activamente en la comisión de la citada infracción tributaria: encontramos el matiz de «activamente», que parece reconducir a las categorías de participación penales.

Sin embargo, a diferencia de lo que ocurría con la anterior LGT, este matiz nos va a posibilitar descartar todas las formas de participación omisiva, de hecho, para autores como MARTÍN FERNÁNDEZ ${ }^{24}$, este matiz restringiría la órbita de actuación del precepto a la cooperación necesaria (CP, art. 65.3). El matiz de «activamente», parece indicar que en la modalidad comisiva ha de mediar dolo, entendido como intencionalidad de realizar la

${ }^{23}$ Cfr. Martín FernándeZ, J.: Responsabilidad del Profesional Tributario como Asesor del Contribuyente, Revista Técnicos Tributarios, $\mathrm{n}^{\circ}$ 23, Diciembre-2005 Madrid págs. 2 y ss.

${ }^{24}$ MARTín FernándeZ op. cit. 23 pág. I2. 
conducta, no cabiendo otras modalidades en las cuales se realiza el presupuesto de hecho de la norma involuntariamente, si bien esto no es meridiano pues puede existir responsabilidad por imprudencia (ver epígrafes posteriores).

\section{III.2. Opciones de Actuación del Asesor Fiscal y Alcance de la Responsabilidad}

Una vez vistos los requisitos necesarios para que entre en juego la responsabilidad tributaria del responsable solidario, vamos a observar cual es el alcance de la misma.

Destacar que esta responsabilidad será distinta si nos encontramos:

- El asesor solo aconseja al cliente con sus conocimientos especializados: Esto puede realizarlo de forma pasiva, informando acerca de las obligaciones tributarias que se deriven una vez realizado el hecho imponible, y de forma activa, dando consejos de planificación fiscal antes de que los citados hechos imponibles se produzcan.

- El asesor actúa como representante del cliente ${ }^{25}$, pudiendo llegar a sustituir para la realización de determinados actos la voluntad del representado. Obviamente, como veremos con posterioridad, en esta modalidad comisiva la responsabilidad será mayor que en la anterior.

A la hora de valorar el alcance de esta responsabilidad, nos encontramos ante el interrogante de saber si se impone una única sanción a todos los coautores o bien una a cada uno de ellos.

Con la LGT/1963 parece que habríamos de inclinarnos por el criterio de una única sanción, aunque solo fuera porque este presupuesto de la responsabilidad solidaria en la LGT/2003 tenía la finalidad de asegurar el cumplimiento de las obligaciones tributarias, y no de imponer sanciones a los coautores o colaboradores en la infracción.

Es evidente que, desde este punto de vista, el asesor fiscal resultaba muy favorecido, ya que el pago por el deudor principal de la totalidad de la cantidad, le exoneraba a él de toda responsabilidad y, si el cliente no pagaba, el asesor siempre disponía de la acción de regreso contra este para reclamarle lo que el asesor hubiera pagado por él.

Es cierto que el cliente podía, a su vez, instar una reclamación civil contra el asesor fiscal por los daños ocasionados por su negligencia, a través de la indemnización por daños y perjuicios derivados de la responsabilidad civil contractual ${ }^{26}$ (bien que, sin ser objeto de este trabajo, merece destacarse que la naturaleza de la responsabilidad no es en absoluto pacifica, pudiendo considerarse en algunos casos de tipo extracontractual).

La Sentencia del Tribunal Superior de Justicia ( en adelante STSJ) de Castilla- La Mancha, de 4-4-1995 consideró, por el contrario, exclusivamente imputable al asesor fiscal la responsabilidad por las infracciones tributarias cometidas por el cliente que suministró los datos diligentemente al asesor fiscal, pero este cometió una infracción por una negligencia grave.

${ }^{25}$ La representación en el ámbito tributario se halla recogida entre otros en los arts. 45,46 y 47 de la LGT/2003 y en los arts. IIO,III y II2 del RGGI.

\footnotetext{
${ }^{26}$ Arts. IIor y s. del Cód. Civil
} 
Pese a ello, la LGT/I963 no parecía ofrecer esta posibilidad directamente en su articulado, ya que ni siquiera preveía la coautoría, solo la responsabilidad solidaria.

Este tema fue objeto de estudio en la LGT/2003, con una fuerte tendencia doctrinal que abogaba por incluir en la misma las formas de participación del Derecho Penal; pero esta posibilidad quedó descartada por la Comisión para el Estudio y Propuesta de Medidas para la Reforma de la LGT, con base a argumentos (que no compartimos) basados, por ejemplo en el hecho de que las modalidades de participación se crean para delitos, y aquí nos hallamos ante infracciones administrativas, que si son leves, pueden dificultar encajar las formas de participación o, que la sociedad no reclamaba esta inclusión de las modalidades de participación.

Sea como fuere, la LGT/2003 no modifica en nada esta cuestión ni introduce las más que deseables modalidades de participación, a pesar de que buena parte de la doctrina considera, que debiera haber dos sanciones individuales y autónomas: para el asesor y para el contribuyente, no teniendo ninguna virtud liberadora la una respecto de la otra.

Cuando el asesor actúa como representante del contribuyente, la prueba de su culpabilidad es más fácil puesto que la relación con el contribuyente es mucho más estrecha, y el campo de actuación del asesor fiscal más amplio, pudiendo apreciar, por lo menos, una Cooperación Necesaria, cuando no directamente una Autoría Mediata.

Los dos supuestos más extremos que nos vamos a encontrar son:

- El asesor representante actúa por su cuenta con total desconocimiento por parte del cliente de las actuaciones del mismo: Aquí podríamos invocar la responsabilidad exclusiva del asesor fiscal siempre y cuando la infracción no derive de forma clara de la ineptitud del mismo, puesto que entonces, la responsabilidad del cliente (que al fin y al cabo es quien elige a su asesor) subsistiría (vid. SAP Burgos 29-3-1999 ${ }^{27}$, que considera autor del delito al asesor fiscal que actuaba como representante del contribuyente y comete un delito de defraudación tributaria con desconocimiento de su cliente). Sin embargo, parece que muchas resoluciones de los Tribunales Económico Administrativos (en adelante TEA) ${ }^{28}$ se inclinan por atribuir una responsabilidad in eligendo o in vigilando al contribuyente, lo cual, dada la inexistencia de requisitos para ser asesor fiscal, y teniendo en cuenta que, precisamente, el contribuyente emplea la diligencia debida en la búsqueda de un profesional para que realice sus obligaciones tributarias, puede no ser del todo coherente.

- Si el asesor se limita a representar a su cliente actuando en su nombre y siguiendo sus instrucciones estrictamente, pero desconoce que con su actividad está llevando a cabo una infracción; parece evidente que, por faltar el elemento subjetivo necesario, la responsabilidad recaerá en exclusiva sobre el cliente.

\footnotetext{
${ }^{27}$ SAP Burgos 79/1999 de 29-3-I999 F.J. $4^{\text {o }}$

${ }^{28}$ Entre otras, merece destacarse la Res. 332/2003 del TEAF de Navarra de 25-I-2006, que en su F.J. $2^{\circ}$ dice: «Tampoco puede oponerse a la aplicación del régimen de estimación indirecta el hecho de que, según sus afirmaciones, fuese un asesor quien efectuase la renuncia al régimen de estimación objetiva de bases imponibles, pues, por un lado, tal manifestación de renuncia es siempre exclusiva responsabilidad del sujeto pasivo afectado (aunque formalmente la realice otra persona) y, por otro, la circunstancia expuesta revelaría nuevamente una actitud negligente de los interesados calificable como culpa in vigilando, al no haberse preocupado de supervisar las actuaciones llevadas a cabo por dicho asesor».
} 
Hemos de pasar a analizar ahora que conceptos alcanza la responsabilidad tributaria del asesor fiscal; acorde con el ya citado art. 42.I.a) la responsabilidad del colaborador en la infracción tributaria se extiende incluso a la sanción, lo cual acaba con las discusiones doctrinales acerca de los arts. 37,38 y 40 de la LGT/1963 acerca de los Administradores de la Persona Jurídica y, por el hecho de que había tesis doctrinales que (nos parece, con base en la Instrucción de 2-II-I995 del Departamento de Recaudación de la AEAT, que resultan erróneas), negaban la inclusión de la sanción en el total de la responsabilidad que cabía imputar al Asesor Fiscal.

De hecho, podríamos postular que, acorde con la LGT/1963, el Asesor Fiscal era responsable único de la sanción y responsable solidario junto con el sujeto pasivo, de los demás elementos integrantes de la obligación tributaria.

Realmente, esta tesis pudiera presentar problemas cuando la analizamos desde el principio de personalidad de la pena no obstante, podría salvarse el escollo postulando que la sanción se le impone al asesor fiscal por su mala praxis y por su colaboración a la infracción (en muchas ocasiones mucho más grande que la del propio cliente)

El art. 42.I.a) es tajante, acabando con estas tesis doctrinales, y postulando la responsabilidad solidaria del asesor fiscal tanto en los elementos de la deuda tributaria, como en la propia sanción, abandonando de este modo la tesis de la sanción exclusiva para el asesor fiscal.

Ahora bien, resulta capital delimitar el contenido de la deuda tributaria a la que se alude en el mencionado art., poniéndolo en relación con el art. 4I.3 el cual postula:

«Salvo lo dispuesto en el apartado 2 del artículo 42 de esta Ley, la responsabilidad alcanzará a la totalidad de la deuda tributaria exigida en período voluntario. Cuando haya transcurrido el plazo voluntario de pago que se conceda al responsable sin realizar el ingreso, se iniciará el período ejecutivo y se exigirán los recargos e intereses que procedan».

Además, el apartado siguiente nos matiza que la responsabilidad no alcanza a las sanciones, salvo las excepciones que se establezcan (como por ejemplo el artículo 4I.I.a).

Acorde con la Guía de la LGT ${ }^{29}$, la responsabilidad alcanzaría la totalidad de la deuda exigida en periodo voluntario excluyendo, lógicamente, las sanciones (por aplicación del art. 4I.3 y por el hecho de que el art. 25.2 de la LGT/2003 señale expresamente que las sanciones no tienen la consideración de obligaciones accesorias), y los recargos del periodo ejecutivo, así como los intereses devengados por el retraso en el pago del sujeto pasivo. Ello no obsta a que el responsable pueda tener que asumir el pago de los recargos de periodo ejecutivo e intereses que por su propia tardanza en el pago se devenguen.

Sin embargo, en nuestra opinión, en el período voluntario, deben considerarse parte integrante de la deuda tributaria, los recargos por presentación extemporánea definidos en el art. 27, y los intereses de demora devengados, cuando es el Inspector de Hacienda quien descubre fallos en las declaraciones tributarias, y regulariza la situación, dándose un nuevo periodo voluntario para el pago $0^{30}$.

\footnotetext{
${ }^{29}$ Cervantes Sanchez-Rodrigo, C.: Guía de la Ley General Tributaria, CISS, Bilbao-2004, pág.Io8.

${ }^{30}$ Cfr. Martin Queralt, J, Lozano Serrano, C., Casado Ollero, G.: Curso de Derecho Financiero y Tributario 20I4. Tecnos Madrid Pág. 246.
} 
Esto cobra más sentido ya que, precisamente por la colaboración del asesor fiscal, la Administración tiene que realizar un procedimiento de investigación para descubrir la infracción tributaria que el asesor ha ayudado a consumar.

Así cobran importancia las previsiones que permiten imponer al asesor fiscal la responsabilidad solidaria en la sanción, si bien es verdad que, cuando el asesor fiscal actué como representante del cliente, sin que este sepa realmente la labor y las gestiones que realiza el asesor fiscal en su nombre, deba imponérsele al asesor fiscal la totalidad de la sanción de una manera exclusiva, sin derecho de repetición de ningún tipo, pues concurre la culpa exclusiva del asesor fiscal en la causación del daño que da lugar a la correspondiente sanción.

\section{III.3. Dolo, Culpa o Negligencia del Asesor Fiscal}

También parece necesario, en mi opinión, que la Administración pruebe que hubo culpa o negligencia en el proceder del asesor fiscal que condujo a la infracción, puesto que, para ser causante o colaborar activamente, a mi juicio se requiere de culpa, dolo o negligencia, no configurándose para el Asesor Fiscal una suerte de responsabilidad objetiva sobre todas las actuaciones tributarias de su cliente, ya que si postuláramos la existencia de dicho régimen en las sanciones, podríamos conculcar el principio de personalidad de la pena y, desde luego, el elemento del tipo de injusto subjetivo existente en la misma.

La Administración Tributaria deberá probar y motivar por tanto, (no siendo necesario a mi juicio que dicha prueba se haga en un procedimiento aparte del seguido contra el sujeto pasivo), que han concurrido estos elementos en el Asesor Fiscal.

Elementos que si llevan a determinar que el poder de actuación del representante era completo y que el cliente en absoluto conocía como se desarrollaba en sus obligaciones con la AEAT habría de imputársele la responsabilidad de la infracción tributaria al representante de forma exclusiva, toda vez que el cliente ya justificó la diligencia debida, en la búsqueda de un profesional que realizara esas tareas por él, habida cuenta de su falta de conocimientos.

Destacar asimismo que, en este ámbito, la presentación de las declaraciones tributarias no tiene la consideración de mero trámite, por lo que la representación no se presume y, por tanto ha de concederse el correspondiente poder, como ha postulado, entre otras, la Sentencia del Tribunal Supremo (en adelante STS) 22-6-200I (rec. 3659/1996)

Hemos de mencionar, el hecho de que en el ámbito del Derecho penal se castiga, obviamente por dolo (lo que va a ser capital para el análisis de la siguiente responsabilidad del asesor fiscal), pero en este caso, y por tratarse de un tercero, va a tener que concurrir un doble dolo: el dolo de participación en la infracción tributaria y el dolo referido a que el sujeto pasivo comete la infracción.

Este hecho ha sido postulado por diversa jurisprudencia, tal como la de la Sentencia de la Audiencia Provincial (en adelante SAP) de Madrid 95/2002 de 19-4-2002 ${ }^{3 \mathrm{I}}$

${ }^{31}$ «Como es sabido, en la participación por cooperación necesaria ha de constatarse un doble dolo. Uno relativo al conocimiento y voluntad del propio acto de cooperación, y otro con respecto a la acción que ha de ejecutar el autor del hecho delictivo con el que se coopera». 
Siguiendo esta línea jurisprudencial, parece que habría que probar la concurrencia de ambos tipos de dolo en el Asesor Fiscal para poder imputarle responsabilidad; ahora bien, resulta muy fácil apreciar el dolo cuando el Asesor Fiscal cobra por su labor de asesoría y mucho más cuando es un representante.

Realmente podríamos postular, bien que puede tener muchos argumentos en contra, que solo habríamos de probar el dolo de participar en la infracción tributaria del asesor fiscal, ya que el art. 42 de la LGT/2003 persigue la colaboración activa de los sujetos en la comisión de infracciones tributarias y, por tanto con la voluntad de participar en la infracción ya debería ser suficiente.

Asimismo, se va a castigar por imprudencia, aunque en mi opinión, no entra dentro de las posibilidades de imputar responsabilidad al asesor fiscal si nos encontramos con una imprudencia levísima y, desde luego, debería matizarse mucho el alcance de esa responsabilidad en los casos de imprudencia leve.

Bien es verdad que, en el caso de la imprudencia del Asesor Fiscal, ya va a incurrir en la mayoría de los casos en una negligencia profesional o ineptitud que nos va a posibilitar, sin excesiva dificultad, responsabilizar al Asesor Fiscal por la infracción tributaria cometida, de hecho, según la entidad de la imprudencia profesional, yo soy participe de que asuma la responsabilidad de forma exclusiva, por suponer la conducta desarrollada, tal entidad que puede atribuirse el resultado lesivo a esta, sin que podamos atribuírsela a un cliente que en muchos casos es desconocedor de la materia.

Ello, nos obligaría a introducir categorías del derecho penal en la LGT/2003, cosa que, a mi juicio, y para este apartado de sanciones, resulta vital puesto que, si no nos moveremos, como ha venido pasando hasta la fecha, en una laguna llena de conceptos jurídicos indeterminados susceptibles de un alto grado de interpretación de los Tribunales (a pesar de que, este poder interpretativo me parece muy adecuado, pero hay que buscar una mayor seguridad jurídica en el sector).

No podemos cerrar el tema de la imprudencia y el dolo sin hacer referencia al error.

- Este error será vencible cuando hubiera podido evitarse empleando la diligencia adecuada.

- El error será invencible cuando, aun empleando toda la diligencia exigible (que en este caso es mayor por tratarse de un supuesto profesional), no se hubiera podido evitar.

Si en asesor concurre un supuesto probado de imprudencia invencible, no se le debe atribuir responsabilidad alguna; lo contrario supondría conculcar buena parte de los principios del derecho penal, y aplicar en un ámbito sancionador tributario en el que no está previsto, una responsabilidad totalmente objetiva.

Pese a que hay doctrina que postula que el asesor fiscal no puede cometer ningún tipo de error invencible, considero que el hecho de ser un asesor profesional, no da lugar a que no pueda cometerse ningún error invencible; puesto que, si bien hay cuestiones inherentes al ejercicio de la profesión que no pueden, en principio ser susceptibles de error, ( y digo en principio porque, dada la carencia de regulación y requisitos para ejercer esta profesión, cabría argumentar mucho acerca de poder exigir por vía sancionadora unos conocimientos que no se exigen por vía civil o administrativa), hay otros de índole más externa, o más vinculados a la apreciación de la Administración, en los cuales el asesor 
puede cometer errores, como viene diciendo la doctrina del Tribunal Constitucional en SSTC 219/1989 y 93/1992.

De hecho, son absolutamente justificables, y así lo ha apreciado el Tribunal Supremo en numerosas sentencias ${ }^{32}$, pequeños errores aritméticos de fácil comprobación por la Administración.

Hemos de matizar, asimismo, que no constituyen error las diferencias razonables en la interpretación y aplicación de normas tributarias que presentan un alto grado de complejidad y de abstracción, y/o que son objeto de polémica; ya que no parece adecuado enjuiciar como error el mero hecho de decantarse por una postura o por otra a la hora de interpretarlas, sin perjuicio de que la Administración tenga derecho a tener un criterio divergente sobre la misma norma, como postulo el TEAC en Resolución de 2I-6-I995 $5^{33}$ :

Por tanto, podemos concluir sin lugar a dudas, que no existe en nuestro ordenamiento tributario una presunción iuris et de iure de conocimiento del asesor fiscal y que, por tanto, en cada caso habremos de examinar si se cumplen los requisitos para calificar la conducta del asesor fiscal como culposa o dolosa, al igual que deberemos hacerlo también para el contribuyente; si bien es cierto que habremos de tomar en consideración las distintas circunstancias de cada uno de los intervinientes y la presunta profesionalidad de los mismos.

\section{Responsabilidad penal del asesor fiscal}

\section{IV.I. Introducción}

Para analizar la responsabilidad penal en la que puede incurrir el asesor fiscal, se hace necesario acotar en este apartado el objeto de nuestro estudio, cual es la responsabilidad derivada del delito de defraudación tributaria recogido en el arts. $305 \mathrm{y}$ 305.bis del Código Penal (en adelante CP).

En lo que respecta al tema derivado del blanqueo de capitales, este será examinado de manera exhaustiva en un apartado siguiente, puesto que tanto los sujetos activos, pasivos, el iter criminis y la acción típica difieren en ambos.

Señalar únicamente que el blanqueo de capitales se encuentra recogido en los arts. 30 I a 304 del CP I995 y que, en ocasiones, este delito encuentra muchos problemas a la hora de entrar en concurso con el delito de defraudación tributaria, como podemos ver en las SSTS 649/1996 de 7-I2-1996 634, I493/1999 de 2I-I2-I996 $6^{35}$, por citar algunas, y sin embargo, podemos destacar otra línea jurisprudencial que se ve plasmada en la STS

${ }^{32}$ Vid doctrina de errores aritméticos presente entre otras en las SSTS de 30-I-20I2( rec. 2374/2008) F.J. $4^{\circ}$ o de I6-2-2009 (rec. 6902/05) F.J. $5^{\circ}$

${ }^{33}$ SÁnCHEZ-Pedroche, op. cit.I4 pág. II 8 : «La Ley no puede alcanzar a sancionar las equivocaciones o errores de calificación jurídica sobre el carácter deducible o no de unos gastos efectivamente producidos y debidamente declarados, en un tema objeto de amplia polémica social, pues obviamente resulta imposible que todos los contribuyentes puedan estar al corriente de unas normas tributarias en constante tramite de modificación y acierten en su interpretación, bajo amenaza de sanción impuesta automáticamente sin tener en consideración su culpabilidad».

\footnotetext{
${ }^{34}$ Sentencia Caso Nécora

${ }^{35}$ Sentencia Caso Roldán
} 
20/200I de 28-3-2001 ${ }^{36}$, que analiza el concurso del delito de defraudación tributaria estableciendo una línea jurisprudencial seguida entre otras por la SSTS III3/2005 de I5-92005 y 906/2009 de 23-9-2009.

\section{IV.2. Naturaleza del Delito de Defraudación Tributaria}

Entremos ahora a analizar la naturaleza del delito de defraudación tributaria, naturaleza que ha sido, sin duda, objeto de numerosas discusiones doctrinales, para lo cual, vamos a partir de distintas teorías enunciadas acerca de su naturaleza:

- Nos encontramos con un delito de naturaleza especial propia: Como postula el autor del artículo ${ }^{37}$, PONT CLIMENTE, estos Autores entre los que se encuentran OCTAVIO DE TOLEDO, MARTÍNEZ BUJAN PÉREZ, AYALA O GRACIA representan la opinión doctrinal mayoritaria y postulan que, el delito de defraudación tributaria requiere de una relación única entre la Hacienda Tributaria y el sujeto activo o defraudador, ya que solo puede considerarse sujeto activo o intraneus a aquel que se haya obligado al ingreso de las distintas cuantías por los distintos tributos.

Por tanto, el intraneus solo podrá ser aquel que las leyes tributarias definan como sujeto pasivo (que, como podemos ver en el artículo 37 de la LGT 2003 es un concepto bastante restringido) retenedor $\mathrm{u}$ obligado a practicar ingresos en cuenta.

Todos los demás posibles intervinientes, entre los que se encuentra el asesor fiscal, habrían de ser calificados como extraneus y, en principio, no podrían ser autores ni coautores de este delito, sino que solo podrían ser imputados por algunas de las formas de participación establecidas en el CP.

Digo en principio, porque hay una discusión dimanante de la naturaleza del delito, acerca de si nos encontramos ante un delito de dominio o ante un delito de infracción del deber, lo cual da lugar a importantes diferencias a la hora de habilitar una respuesta penológica para los asesores fiscales, no obstante, lo que parece claro es que, la jurisprudencia del TS ha considerado este delito como un delito especial propio, como puede verse en la STS 774/2005 de 2-6-2005, que recoge la doctrina creada acerca de este tema, entre otras, por la STS 2069/2002 de 5-12-2002 F.J. ${ }^{03^{8}}$,o por la STS 974/2012 de 5I2-20I2, F.J. 22.

Ahora bien, dentro de la calificación del delito como un delito especial propio, se hace necesario aludir a las dos teorías que antes mencionábamos acerca de si hemos de basarnos en calificar el delito como de dominio ${ }^{39}$, teoría que se basa en el hecho de que no todos los delitos especiales han de ser de infracción del deber, puesto que pueden ser

\footnotetext{
${ }^{36}$ Sentencia Caso Urralburu

${ }^{37}$ Pont Climente, J. F.: «Responsabilidad penal del asesor fiscal. Incidencia de la normativa relativa al blanqueo de capitales», Rev. Temas Tributarios de Actualidad, AEDAF, 2I-7-2005, Madrid, pág. 5 y ss.

${ }^{38}$ «El delito fiscal, al menos en la modalidad de elusión del pago de tributos, que aquí interesa, se configura como un delito de infracción del deber de contribuir al sostenimiento de los gastos públicos mediante el pago de tributos, conducta esencialmente omisiva. Se configura como un delito especial propio, de naturaleza patrimonial y además de resultado, siendo el bien jurídico protegido el patrimonio de la Hacienda Pública en su manifestación relativa a la recaudación tributaria»

${ }^{39}$ Cfr. Choclan Montalvo, J.A.: Responsabilidad de auditores de cuentas y asesores fiscales, Bosch, Barcelona2003.pags 80 y ss.
} 
delitos, en los que una persona en principio extraneus (donde entra el asesor fiscal) puede tomar la posición de dominio social típico (basado en la teoría del dominio del hecho) del intraneus, por ejemplo representándolo en sus tareas tributarias, y por tanto, podrían ser castigados como autores o coautores.

Otros autores postulan la teoría tradicional, basada en la naturaleza del delito como un delito de infracción del deber, que solo admitiría la participación de extraneus, en ningún caso su autoría delictual, ya que el deber corresponde exclusivamente al sujeto pasivo, retenedor $u$ obligado a ingresar en cuenta (incluso se postula si cabria, basándonos en esta teoría, la autoría mediata del extraneus puesto que, por más que hiciera este, no podría vulnerar un deber que corresponde en exclusiva al intraneus).

Por último, SILVA SÁNCHEZ ${ }^{4}$, postula que el delito de defraudación tributaria es un delito especial propio, que aúna las dos teorías, en el sentido de que es necesario, por un lado, infringir el deber, y por otro, es un delito en el que cabe la delegación de dominio típico al extraneus, pero como, de todas formas, el extraneus no ha vulnerado el deber personal del intraneus, debe serle atenuada la pena, atendiendo, entre otros, al principio de analogía in bona partem.

- Por último, cabe mencionar la clasificación de este delito como un delito de naturaleza común: esto querría decir que pudiera cometerlo cualquier persona, puesto que, lo relevante, desde el punto de vista típico, es el ingreso en la Hacienda Tributaria de cantidades inferiores a las debidas, o incluso la ausencia de ingreso, siendo irrelevante para la naturaleza penal quien deja de ingresarlas. En este sentido, se han pronunciado autores como PÉREZ ROYO ${ }^{4}$.

Realmente, resulta evidente que, con esta interpretación, la autoría en este delito se ampliaría mucho y sin duda, podría llegar a afectar al asesor fiscal en concepto, esta vez sí, de intreaneus del delito.

Sin embargo, en base a la doctrina mayoritaria y a la abundante jurisprudencia en tal sentido, hemos de postular, sin ningún género de dudas, que el delito de defraudación tributaria, al menos en su redacción actual, se debe configurar como un delito especial propio.

Asimismo, especialmente cuando hablamos de representación, considero adecuado analizar su naturaleza desde el prisma de la teoría del dominio del hecho, para no restringir excesivamente el arco de sujetos pasivos y, creo que hemos de considerar la posibilidad de que el extraneus pueda ser penado en concepto de autor, en base a la cesión del dominio del hecho típico.

Para los demás casos, solo podemos atribuir al asesor fiscal participaciones en el hecho delictual, y no propiamente autorías o coautorías, lo cual, como veremos más adelante, no ha de desembocar necesariamente en una reducción de la respuesta punitiva.

\footnotetext{
${ }^{40}$ Cfr. Silva Sanchez, J.M.: «Determinación de la pena y responsabilidad civil en el delito fiscal. Una aproximación critica a la doctrina de los tribunales», en Estudios penales en homenaje al profesor Cobo del Rosal / coord. por J. C. Carbonell Mateu, 2005, págs. 899-924. Valladolid Págs. 7 y I3.

${ }^{41}$ Cfr. Perez Royo, F: Los delitos y las infracciones en materia tributaria. Instituto de Estudios Fiscales, I986 Madrid.
} 
Aun y así, a nuestro juicio, lo dicho anteriormente, no puede negar que el delito de defraudación tributaria se configura mayoritariamente como un delito de infracción del deber, puesto que nos hallamos ante una lesión de un deber del sujeto pasivo con la Hacienda Pública, un deber consistente en ingresar a tiempo las cantidades debidas, como expresión del deber del contribuir postulado en el art. 3I.I de la $\mathrm{CE}^{42}$, como ha dicho, entre otras, la STS I336/2002 de 15-7-2002, en su F.J. $2^{\circ}$.

Esta cuestión no resulta baladí desde otro punto de vista, tal y cómo es el hecho de que el sujeto pasivo no realice una conducta típica y antijurídica acorde al CP; en ese caso, si seguimos la tesis de la participación del asesor fiscal, hay que tener en cuenta que nos encontraríamos con serios problemas a la hora de punir al partícipe, sin que haya autor, pues ha sido enunciado por numerosa jurisprudencia y doctrina que, para que hablemos de participación, hemos de hablar antes de autoría o, dicho de otro modo, no hay participe de un delito si nadie asume la autoría de la comisión delictual, ya que de lo contrario desvirtuaríamos la propia palabra de participe.

Por último, merece señalarse un matiz que, puede variar la punibilidad del asesor fiscal, y que viene dado por la actual redacción del art. $305 \mathrm{CP}^{43}$, que incluye la obtención de devoluciones indebidas; en este caso, a diferencia del anterior caso estudiado, en donde hablábamos del incumplimiento de una obligación de hacer (ingresar las respectivas cantidades en concepto de Tributos a la Hacienda Pública), para obtener devoluciones tributarias no hace falta ser sujeto pasivo ni obligado tributario.

Lo cual da lugar a que ya no hablemos de un deber especifico, sino de una cierta obligación de no dañar al Erario Público; obligación que puede ser infringida, en mayor o menor medida, por casi cualquier persona y que da lugar a una cierta consideración en esta modalidad de delito común.

Esto da lugar a que podamos considerar al asesor fiscal un intraneus, pues ya no hablamos de un delito especial de infracción del deber.

\section{IV.3. Punibilidad del Fraude de Ley y Negocios Simulados}

Debemos pararnos a analizar, antes de las distintas formas de actuación del asesor fiscal y la responsabilidad dimanante de ellas, la relación que existe entre la Normativa Tributaria y la Normativa Penal, para así responder a la pregunta: ¿Podemos punir penalmente algo que no conlleva estrictamente una sanción desde el punto de vista tributario?

Esta pregunta se nos va a plantear especialmente con el Fraude de Ley tributario y su relación con los negocios simulados.

El Fraude de Ley se encuentra planteado en el art. I5 de la LGT/2003, mientras que la Simulación se encuentra en el art. I6.

\footnotetext{
${ }^{42}$ Dice: «Todos contribuirán al sostenimiento de los gastos públicos de acuerdo con su capacidad económica mediante un sistema tributario justo inspirado en los principios de igualdad y progresividad que, en ningún caso, tendrá alcance confiscatorio».

${ }^{43}$ Vid art. 305 de la Ley Orgánica Io/I995, del Código Penal (vigente hasta I-7-20I5).
} 
La diferencia conceptual entre ambos es que, en la Simulación hablamos de un ocultamiento de actos o negocios, mientras que en el Fraude no existe tal ocultamiento, sino que utilizamos negocios notoriamente artificiosos para conseguir el objetivo que pretendemos, con objeto de aumentar el ahorro fiscal, por ejemplo minorando la base imponible; como nos define la STC I20/2005 de 10-5-2005. Nos vamos a encontrar con que en el Fraude no se imponen sanciones tributarias mientras que en la Simulación sít ${ }^{44}$.

La respuesta penal a la Simulación, no ha presentado problemas en la jurisprudencia cuando concurría todo el elemento del tipo, pero si los ha presentado en el caso del Fraude Fiscal.

Nos vamos a encontrar con que existía doctrina del TS que venía a considerar que, aunque el fraude fiscal no capacite a la AEAT para imponer sanciones, si cumple todos los elementos del tipo penal es sancionable en el orden jurisdiccional penal como delito de defraudación tributaria; esta doctrina fue postulada, entre otras, por la STS 751/2003 de 28II $-2003^{45}$

Asimismo, se postulaba que, aunque la ingeniería fiscal no fuera sancionable en vía tributaria si lo podía ser en vía penal.

Afortunadamente, esta doctrina fue modificada por las SSTC 48/2006 de 13-2$2006^{46}$, y 120/2005, de 10-5-2005 no es, ni puede ser, delito de defraudación tributaria, todo lo contrario de lo que ocurre en el caso de la Simulación, en el cual sí que nos podemos hallar ante un delito de defraudación tributaria.

IV.4. El Asesor Fiscal como Consultor48.

Hemos de analizar ahora las diferentes actuaciones que puede llevar a cabo el asesor fiscal, diferenciando en primer lugar algunas de las actuaciones que el asesor puede realizar como consultor, para posteriormente analizar la posición del asesor fiscal como representante.

Como consultor hay que destacar:

- El asesor fiscal, de acuerdo con el contribuyente, comete la defraudación tributaria: Este supuesto va a tener una solución compleja desde el punto de vista de la responsabilidad penal, según consideremos que nos hallamos ante una actuación que conlleva el impago de ingresos ( y que como hemos apuntado anteriormente solo podemos hablar aquí de participaciones, nunca de autorías), u obtener devoluciones indebidas ( en

${ }^{44}$ Cfr. Larro Parra, M ${ }^{\mathrm{a}}$ J.: El Fraude a la Ley Tributaria. Las defraudaciones contra la Hacienda Pública Tesis Doctoral Editorial Universidad de Granada-20ı2. Págs. 89 y ss.

${ }^{45}$ F.J. 38:«Es decir, el fraude de ley no es típico o sancionable administrativamente por sí mismo, pero tampoco exime de la responsabilidad penal que corresponda, en su caso, por los actos efectivamente realizados en persecución de un resultado prohibido por el ordenamiento o contrario al mismo, cuando estos actos, por si solos, revistan todos los caracteres de una infracción penal».

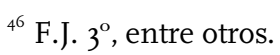

${ }^{47}$ FF.JJ. $4^{\circ}$ y $5^{\circ}$, entre otros.

${ }^{48}$ SÁNCHEZ-PEDROCHE, op.cit. I4. págs. I80 y ss. 
las que puede caber la condena al asesor fiscal como intraneus y por tanto podemos acudir a los conceptos de autoría o coautoría).

En el primer supuesto parece claro que, a lo máximo que puede llegar la responsabilidad del asesor fiscal es a la cooperación necesaria o a la inducción.

- Para definir la cooperación necesaria y diferenciarla de otras formas de participación, podemos acudir, o bien a la teoría de la condición sine qua non que postula que «será cooperación necesaria cuando el cooperador realice una conducta sin la cual el delito no se hubiera cometido», a la teoría de los bienes escasos, cuando colaboramos realizando algo difícil de conseguir por otros medios, o a la teoría del dominio del hecho, si quien ha colaborado pudo impedir la comisión del delito si no lo hubiera hecho, si bien todas ellas tienen un nexo común, y es que el cooperador necesario no puede realizar los actos ejecutivos del tipo puesto que, sino hablaríamos de coautoría. Por ejemplo la STS I070/20II de I3-IO-20II considera relevante, para apreciar la distinción entre la coautoría y la cooperación necesaria, la contribución accesoria de la conducta frente a la acción principal que comete el hecho delictivo al igual que en la STS 832/2007 de 5-I0-2007.

Vamos a encontrarnos por tanto que dada la especialización de los conocimientos del asesor fiscal y su probabilidad de realizar conductas que tengan una cierta relevancia en la consecución del tipo delictual, hablaremos, en muchas ocasiones, de cooperación necesaria, un ejemplo de una condena al asesor fiscal por cooperación necesaria lo encontramos en la Sentencia de la Audiencia Nacional (en adelante SAN) Sala Penal rec. I/20I2 de 3-4-20I3 F.J. $2^{\circ}$.

- La inducción presenta menos problemas de definición y, siguiendo a MUÑOZ $\mathrm{CONDE}^{49}$, podemos definirla como la conducta del inductor que hace surgir en otra persona (inducido) la idea de cometer un delito, pero quien decide realizarlo, y ostenta el dominio del hecho, es el inducido. Dicha inducción tiene que cumplir, en el caso que nos ocupa, el requisito de relevancia, (el asesor tiene que generar con su conducta un influjo psíquico suficiente en la voluntad del inducido), de incremento del riesgo (con su conducta debe incrementar notablemente el riesgo de que el delito se produzca), ha de basarse en una relación directa entre el asesor y el contribuyente autor, y ha de ser eficaz para que el inducido decida cometer el delito y comience a ejecutarlo. Es evidente que no cabe condenar al asesor por inducción por imprudencia, tampoco cuando se limita a avisar al cliente de que una determinada actuación puede ser delictiva y este la realice. Por tanto, aquí nos encontraremos con un problema de prueba sustancial.

En el segundo supuesto, vamos a encontrarnos con el concepto de coautoría, que ha sido muy debatida por numerosas opiniones doctrinales, sobre todo analizando si existe el deber de conocer que la información suministrada por el cliente es veraz y, si existe el deber de denunciar a la Administración Tributaria las falsedades que cometa el cliente.

Aquí resulta obligado analizar la normativa de blanqueo de capitales, que se encuentra, entre otras, en el RD 304/20I4 de 5 de mayo ${ }^{50}$, y en la Ley Io/2010 de 28 de

\footnotetext{
${ }^{49}$ Muñoz Conde, F.: Derecho Penal parte General, Tirant lo Blanch $8^{\circ}$ Edición 2010 Valencia págs. 443 y ss.

${ }^{50} \mathrm{RD} 304 / 2014$, de 5 de mayo, por el que se aprueba el Reglamento de la Ley Iо/2010, de 28 de abril, de prevención del blanqueo de capitales y de la financiación del terrorismo
} 
abril $1^{5 \mathrm{x}}$, las cuales analizaremos cuando hablemos del blanqueo de capitales. Sin embargo, cabe responder que, el asesor fiscal no tiene la obligación de conocer que la información suministrada es veraz (aunque en estas leyes se establecen ciertas cautelas que ha de tomar el asesor fiscal en su desarrollo profesional con el cliente, incluyendo en algunos casos comunicaciones al Servicio Ejecutivo de la Comisión de Prevención de Blanqueo de Capitales e Infracciones Monetarias (en adelante SEPBLAC)), en lo que respecta a la segunda cuestión, nos vamos a encontrar con mayor debate, ya que van a verse implicadas cuestiones como el secreto profesional del asesor fiscal. Sin entrar en los límites de este secreto profesional, ya que hablare de ellos a colación del blanqueo de capitales, y basándome en jurisprudencia constitucional, destacar que si se cumplen ciertos requisitos, los asesores fiscales pueden no estar obligados a informar al SEPBLAC, acorde con la Ley ı/20ıo. Además, el delito de defraudación tributaria no está dentro de los delitos del art. $450 \mathrm{CP}$, por tanto, un posible argumento consistiría en que el asesor no tiene la obligación de denunciar estos delitos, máxime cuando la Ley ıо/20ıо se refiere al Blanqueo de Capitales y al Terrorismo, no a la defraudación Tributaria per se.

Por todo ello, el hecho de que pueda existir coautoría es, cuanto menos, muy debatido, a la luz de los planteamientos anteriores (solo podría serlo en aquel delito que califiquemos como delito común, nunca en los delitos especiales, como hemos visto anteriormente).

Destacar, que podemos encontrarnos con graves dificultades para apreciar ciertas eximentes al asesor fiscal cuando este defrauda como consecuencia de las órdenes emitidas por el cliente. ${ }^{52}$ Podría caber el estado de necesidad, aunque resulta francamente complejo de probar.

Sí que podremos observar, con relativa facilidad, el agravante del art. 22.3 CP, puesto que la orden siempre ira acompañada de una remuneración, lo único que habremos de probar será la relevancia de la misma en la actuación del asesor.

- El asesor defrauda a través del cliente, con total desconocimiento del mismo: Aquí resulta clara la posibilidad de encuadrar la conducta del asesor en la autoría mediata, utilizando al cliente como mero instrumento. Esta autoría mediata del asesor fiscal, ha sido estudiada, entre otras sentencias, por la SAP Zaragoza rec. 92 /2009 de 3I-7-2009, F.J. $4^{053}$. Realmente, aquí lo importante será poder probar el absoluto desconocimiento, por parte del cliente, de las actuaciones desarrolladas por el asesor fiscal.

- El asesor fiscal comete el ilícito penal porque la información suministrada por el cliente no era veraz o estaba incompleta: En este caso resulta evidente que el asesor fiscal no

\footnotetext{
${ }^{51}$ Ley iо/20ıо, de 28 de abril, de prevención del blanqueo de capitales y de la financiación del terrorismo.

${ }^{52}$ Cfr. Muñoz Conde, op. cit. 49

${ }^{53}$ «Desde el punto de vista de la Sala, la determinación de la autoría en los delitos económicos empresariales de carácter especial como el delito fiscal, no plantea ninguna dificultad para admitir la autoría mediata, ya que los 'delitos especiales' al contrario de los llamados 'delitos de propia mano' no necesitan ser realizados directacorporalmente por su autor, sino que éste puede servirse como mediador de otra persona(...) Ahora bien, si el gestor o asesor fiscal a quien se encomienda la realización de las actuaciones necesarias tendentes al cumplimiento de la obligación, incumple dolosamente el mandato recibido, sin conocimiento del representado, puede ser responsabilizado en concepto de autor por delito fiscal, conforme al precepto indicado; aunque no sea él personalmente el sujeto pasivo de la relación jurídico-tributaria. Cuando actúa en connivencia con el deudor tributario, entonces podrá deducirse responsabilidad por su contribución al hecho como partícipe (inductor, cooperador necesario o cómplice no necesario)».
} 
ha obrado con dolo, ya que supone que lo suministrado por el cliente era cierto o completo $y$, en base a ello, realiza su labor. Este tema ha sido estudiado, entre otras, por la SAP Badajoz de II-4- 2OII rec. I2I/2OI3 FJ $2^{\circ}$. En nuestra opinión, no debería tener el asesor fiscal responsabilidad penal alguna, ya que en cierto modo, y siguiendo al autor SÁNCHEZ PEDROCHE ${ }^{54}$, nos encontraríamos ante «una autoría mediata donde el intraneus (contribuyente) se serviría del extraneus (asesor) como instrumento para la comisión del delito».

- El asesor fiscal actúa de una manera neutral, como un mero consejero: para explicar este supuesto imaginemos a un asesor fiscal que, en su labor de consultor, asesora al contribuyente sobre la manera idónea de minimizar su presión fiscal (algo que constituye su labor principal) pero, una vez asesorado y dados los conocimientos jurídicos precisos al cliente, este los selecciona y, utilizándolos conforme a sus propios intereses y de manera individual, comete la defraudación tributaria.

Para resolver la disensión acerca de si al asesor ha de considerársele, de algún modo, participe o no, y a partir de qué momento, hemos de considerarlo participe, hemos de acudir a las diversas Teorías de los Actos Neutrales. Esta disensión doctrinaria empezó en Alemania y, de hecho, alguna teoría ${ }^{55}$, que voy a citar a titulo introductorio, se va a basar en decisiones de sus Tribunales:

- Para Roxin, la diferencia en estas acciones surge del estudio del dolo: Hemos de analizar si el asesor realizó esa acción con conocimiento seguro de que el autor iba a delinquir (dolo directo), o si por el contrario, el asesor consideró que su acción podía contribuir a que una persona cometiera el delito (dolo eventual). Desde el mismo momento que el asesor conociera con total seguridad que el cliente iba a cometer el delito, estaría participando en él si realiza alguna acción de las mencionadas, sin embargo, no puede participar por el mero hecho de realizar una acción que pueda ser utilizada por el cliente para delinquir, si este no tiene la certeza de que el cliente realmente la va a usar para delinquir; ya que, en principio, se supone que el cliente no es un delincuente en potencia. Esta teoría ha sido mencionada en la sentencia del 3.Strafsenat ${ }^{56}$ (de I3-4-I988 y del 5.Strafsenat de 23-6-1992.

- Para JAKOBS, la diferencia se lograría a través del estudio de lo que él llama la «prohibición de regreso» que consiste en que, en palabras de SANCHEZ PEDROCHE «el mero intercambio de una información o la prestación de un objeto o servicio ente personas con preferencias diversas constituye un asunto propio de cada cual, prestación que además puede obtenerse de cualquier sitio y que no entraña riesgo alguno, aunque el autor la utilizara para cometer un delito» ${ }^{57}$. Evidentemente, esta teoría puede sufrir como critica que, quienes prestan servicios a un cliente que sabe que los va a usar para delinquir, han de ser partícipes de algún modo en el delito cometido.

\footnotetext{
${ }^{54}$ Cfr. SÁnCheZ-Pedroche, J.A op. cit. I4 pág. 202

${ }^{55}$ Cfr. SAnChez-Pedroche op. cit. I4 págs. 235 y ss.

${ }^{56}$ Tribunal de la Jurisdicción Alemana

${ }^{57}$ El autor sigue a BLANCO CORDERO, I.: Límites a la participación delictiva. Las acciones neutrales y la cooperación en el delito, pág. 237
} 
Lo que ha de destacarse de estas, y otras teorías, es que no podemos caer en el error de considerar que el asesor fiscal debe abstenerse de cometer o de emitir cualquier tipo de acto o manifestación que, en abstracto fueran susceptibles de ayudar a la comisión de un delito; porque, en ese caso, directamente estaríamos impidiendo el desarrollo de la profesión, no solo del asesor fiscal, sino de otras muchas profesiones (pensemos que se tendría que abstener todo agente de bolsa de realizar transacciones, pues con esas transacciones igual podemos cometer un delito de estafa o de blanqueo de capitales).

En este sentido, deberemos postular que, la acción desarrollada por el sujeto no resultará punible cuando se ajuste a las exigencias legales marcadas por sus normas reguladoras (tanto jurídicas como propias de su ámbito empresarial) y, siguiendo el criterio de un hombre medio, no se hubiera tenido un grado de certeza de que, realizando esa acción, el cliente iba a cometer el delito.

En tal sentido, merece destacarse la STS Sala $2^{\circ} 928 / 2006$ F.J. $6^{\circ}$ (entre otros) de 510-2006.

Dentro de este apartado, merece destacarse la aplicación de los atenuantes; ya hemos visto que la opinión mayoritaria considera el delito de infracción tributaria como un delito especial propio de infracción del deber, por lo tanto, en esta modalidad, el asesor fiscal nunca podría ser autor; sin embargo, otra doctrina (que comparto), considera que en uno de los matices del delito podemos encontrarnos con un delito de naturaleza común y, por tanto, susceptible de autoría por el asesor fiscal.

Las diferencias entre la autoría y las formas de participación, además de las ya vistas, se encuentran en la aplicación de atenuantes.

De forma muy somera, pues esta cuestión no ocupa el aspecto vertebral del presente trabajo, enunciaré el régimen actual de la aplicación de las atenuantes al asesor fiscal partícipe.

Lo primero que hay que decir es que, al menos en abstracto y sin atenuantes, el cooperador necesario o el inductor, acorde con el art. 28 del CP, son considerados autores.

Ello, evidentemente en un delito como el que nos ocupa (por lo menos en su modalidad omisiva), debería comportar que al autor contribuyente se le castigara de la misma manera que al asesor fiscal inductor, pues el asesor fiscal se equipara ex art 28 al autor.

Ahora bien, para corregir la evidente falta de correlación entre la culpabilidad de uno y del otro,(recordemos que el contribuyente infringe un deber propio, mientras que el asesor fiscal a lo sumo ayuda o induce a cometer esa infracción, pero no infringe ningún deber propio), aparece el art. 65.3 del $\mathrm{CP}^{58}$ :

Es doctrina jurisprudencial asentada la aplicación en los casos de delitos especiales, o propios de este artículo, al extraneus, como podemos observar en la STS Sala $2^{a}$, 990/20I3 de 30-I2-20I3 (F.J. $8^{\circ}$ ) que, a su vez, hace referencia a la STS Sala $2^{\mathrm{a}}$, 8I7/2008 de

\footnotetext{
${ }_{58}$ «Cuando en el inductor o en el cooperador necesario no concurran las condiciones, cualidades o relaciones personales que fundamentan la culpabilidad del autor, los jueces o tribunales podrán imponer la pena inferior en grado a la señalada por la ley para la infracción de que se trate».
} 
II-I2-2008 (F.J. $5^{\circ}$ ) señala que, si bien este precepto se encuentra vigente desde la LO I5/2003 que reformó el CP.

Este precepto viene a recoger una línea jurisprudencial que consideraba aplicable la atenuante del antiguo art. 65.I, en forma analógica in bonam partem, atendiendo a la circunstancia de que la falta de la relación personal que sirve de fundamento a la punibilidad, tiene que ser asimilable a una atenuante, como postuló la STS, Sala $2^{\text {a }}$, I2-2I992, línea seguida por sentencia del caso Juan Guerra (STS de 24-6-I994) entre otras.

Igualmente, la STS del año 20I3 se encarga de destacar que, la aplicación de la atenuante del art. 65.3 es facultativa, opinión que sigue a la línea jurisprudencial inveterada que podemos observar, por ejemplo, en la STS Sala $2^{a}$ 636/20I2 de I3-7-2012 de julio o en la STS Sala $2^{a}$ I074/2004 de I8-10-2004.

Del seguimiento de toda esta línea jurisprudencial, podemos aseverar que, si bien es facultativa, la atenuante del art. 65.3, es directamente aplicable al asesor fiscal en el delito de defraudación tributaria en su aspecto estudiado, y, de hecho, se aplicará en un gran número de ocasiones, cuando sea cooperador necesario o inductor.

Destacar que no se aplicará cuando nos encontremos con supuestos de complicidad, ya que estos ya comportan una rebaja específica independiente de esta atenuante.

\section{IV.5. El Asesor como Representante}

En este caso no vamos a encontrarnos con tantos problemas para definir la autoría del asesor fiscal, ya que hemos de partir del estudio del art. 3I del $\mathrm{CP}^{59}$,el cual surge a partir del art. I5bis, introducido por la Ley Orgánica 8/1983 de 25 de junio en el CP/ı973. Este artículo surge para evitar la impunidad en los delitos especiales propios, cuando los cometen representantes de las personas físicas o personas jurídicas las cuales tienen los requisitos para cumplir el delito especial y que, sin este artículo nunca podrían cometer dicho delito, al no reunir ellos los concretos requisitos de los delitos. Además, merece destacar que este artículo, cuando era el I5.bis, ha sido estudiado jurisprudencialmente por la STC 253/1997 de 20 de julio ${ }^{60}$.

Hay que destacar estos tres supuestos de representación (siguiendo a los ya vistos en el caso del papel como asesor):

- El asesor, de acuerdo con el contribuyente, comete la infracción tributaria: Aquí estaremos ante un supuesto de coautoría, si observamos un acuerdo conjunto entre el cliente y su representante para defraudar. Ahora bien, nos vamos a encontrar con la necesidad de que dicha representación realmente exista, a pesar de que, siguiendo a la doctrina mayoritaria, parece que bastaría con que el asesor actuara en nombre del representado, aunque no se hayan cumplido todos los requisitos formales de la

\footnotetext{
59 «El que actúe como administrador de hecho o de derecho de una persona jurídica, o en nombre o representación legal o voluntaria de otro, responderá personalmente, aunque no concurran en él las condiciones, cualidades o relaciones que la correspondiente figura de delito o falta requiera para poder ser sujeto activo del mismo, si tales circunstancias se dan en la entidad o persona en cuyo nombre o representación obre».

${ }^{60}$ Torres Gella, F. J.: «Autoría y otras formas de participación en el delito fiscal», Rev. Carta TributariaMonografías, n I6, Quincena I6/30-9-2009, CISS-LA LEY. Madrid Págs. 3 a 2I.
} 
representación. Además, podemos postular que el representante debe actuar con dolo de forma consciente, cometiendo el ilícito penal, si bien no hay ningún problema a mi juicio para admitir que pueda actuar con dolo eventual, aunque, eso sí, parece que para poder aplicársele este artículo, el asesor ha de saber que representa a su cliente y que, por tanto, puede obrar en nombre de la misma y que sus decisiones vinculan al cliente.

- El asesor defrauda con desconocimiento por parte del cliente: Aquí vamos a poderle imputar, en concepto de autor, al asesor fiscal el delito de infracción tributaria. Eso sí, nos encontraremos con más problemas para imputar alguna clase de responsabilidad al representado, podemos basarnos en la SAP Madrid 6I/2002 de II-2-2002 (F.J. $2^{\circ}$ ), que absuelve por concurrir un error de prohibición al empresario, con muy bajo nivel de cultura y alfabetización, que delegó todos los temas fiscales en su asesor fiscal y este cometió el delito. Sin embargo acerca de esta cuestión hemos de señalar que ${ }^{6 r}$ el error de prohibición ha de ser probado por quien lo alega, no bastando para probar este error, acreditar que se tiene un asesor fiscal o que este calificó de una determinada manera la operación ilícita; como viene exigiendo la jurisprudencia, por ejemplo la STS 539/2003 de 30-4-2003 (F.J. Décimo).

- El asesor es utilizado por el contribuyente para defraudar: en este caso, a mi juicio, no puede existir responsabilidad penal imputable al asesor fiscal, pues es bastante evidente que carece del dolo necesario para cometer la acción; en cualquier caso estaríamos ante una imprudencia que no cabe en este delito como ya ha sido postulado por la jurisprudencia.

\section{IV.6. Excusa Absolutoria}

Si bien el análisis del delito de defraudación tributaria no es el objeto principal de este trabajo, no podemos dejar de explicar la excusa absolutoria, que no solo tiene un trascendental impacto en la responsabilidad penal del contribuyente sino también, y como no podía ser de otro modo, en la responsabilidad penal de su asesor fiscal.

Esta figura, a pesar de no estar exenta de polémicas, no es única de nuestro ordenamiento jurídico encontrándose, acorde con J. PEDROCHE, disposiciones similares en el ordenamiento jurídico francés o norteamericano.

En nuestro ordenamiento, la excusa absolutoria para el delito de defraudación tributaria se halla recogida en el art. 305.4 del CP, la actual redacción de este precepto viene dada en el marco de la LO 7/20I2 de 27 de diciembre ${ }^{62}$, que se promulga en un año en el cual tuvo lugar la célebre Amnistía Fiscal.

El citado art. 305.4 permite, de facto, evitar el castigo por quienes hubieran cometido el delito de defraudación tributaria, si regularizan su situación y cumplen los requisitos del apartado 4, o sea reconociendo y pagando completamente la deuda tributaria antes de que la Administración Tributaria les notifique que ha iniciado las diligencias para comprobar o averiguar la deuda tributaria objeto de la regularización o, si no se inician, antes de que el Ministerio Fiscal, Abogado del Estado o representante de la Administración

\footnotetext{
${ }^{61}$ Jufresa PatAu, F. De P.: «El Delito Fiscal a la luz de las últimas reformas del Código Penal», Rev. La Ley Penal LA LEY, Madrid 20I4

${ }^{62}$ Ley Orgánica 7/20I2, de 27 de diciembre, por la que se modifica la Ley Orgánica I0/1995, de 23 de noviembre, del Código Penal en materia de transparencia y lucha contra el fraude fiscal y en la Seguridad Social.
} 
competente le ponga una denuncia o querella, o antes de que el Juez o el Fiscal realicen actuaciones que le permitan tener conocimiento formal de la iniciación de diligencias ${ }^{6_{3}}$.

Sobre la naturaleza jurídica de este precepto, pese a que lo llamemos Excusa Absolutoria, se han emitido estas tres teorías, que solamente me limitaré a enunciar de una manera somera:

- No estamos ante una excusa absolutoria, sino que, de hecho, lo que sucede es que para que haya delito fiscal ha de haber ausencia de regularización, pues esta ausencia es un elemento el tipo y por tanto el tipo de injusto se consumaría cuando se inicien las actuaciones de comprobación o inspección, cuando se formule denuncia o querella contra el autor o cuando se le notifique el inicio de diligencias. Esto plantea evidentes problemas, ya que la consumación del tipo delictual dependería de hechos ajenos al obligado tributario y, además, la prescripción se retrasaría hasta la consumación, lo cual produciría un efecto cuando menos paradójico, cuando se denuncia se consuma el delito y comienza a correr la prescripción, pero además como la denuncia interrumpe la prescripción del delito, el mismo día que comenzara a correr la prescripción, esta se suspendería.

- La regularización actúa como una causa de exclusión de la antijuridicidad y no como una excusa absolutoria: aquí uno de los problemas que existen es que parece lógico postular que estas causas de exclusión de la antijuridicidad han de concurrir cuando se consuman los hechos, no, por ejemplo 3 años más tarde.

- La regularización es una excusa absolutoria: Como aparece definida en la Enciclopedia Jurídica ${ }^{64}$. Aquí no se exige que la excusa concurra cuando se consuma el delito, pudiendo, en opinión de varios autores, según el autor del artículo son entre otros SERRANO GonZÁlEz De Murillo y Merino JarA, concurrir después. De hecho esta opinión también se mantiene en la Consulta 2/2009 de la Fiscalía General del Estado ${ }^{65}$. Ahora bien, a esto podría obstarse la actual redacción del art. 305.I CP que, parece que lo configura como un elemento negativo del tipo y no como una excusa absolutoria ${ }^{66}$.

Es necesario ahora acudir a la Circular 4/i997 de la Fiscalía General del Estado (en adelante FGE $)^{67}$, de la cual podemos sacar los siguientes supuestos de actuación del asesor fiscal:

- En esta consulta el Ministerio Fiscal afirma «Cuando los partícipes en el delito hayan cooperado de alguna forma a la regularización se verán favorecidos por la exención de responsabilidad». Esta cooperación parece adecuado considerarla en un modo amplio, y siguiendo el criterio del Ministerio Fiscal, bastará para apreciar la cooperación del asesor

\footnotetext{
${ }^{63}$ Sanz Díaz-Palacios, J.A.: «Regularización tributario y delito fiscal art. 305.4 del Código Penal» Rev. Impuestos, $\mathrm{n}^{\circ}$ II, Secc. Dictámenes, Madrid Noviembre 20I4, pág. III.

${ }^{64}$ «Figura jurídica prevista para excluir la pena atribuible a un hecho que es típico, antijurídico, culpable. Estas excusas absolutorias eximen, en consecuencia, a su autor (no a los partícipes) de la responsabilidad criminal (...). Se trata, según la opinión doctrinal más generalizada, de circunstancias personales que, por estrictas razones de utilidad o conveniencia, determinan la exclusión de la pena en un comportamiento antijurídico y culpable».

${ }^{65}$ Consulta 2/2009 de la Fiscalía General del Estado, interpretación del termino regularizar en las excusas absolutorias previstas en los arts. 305.4 y 307.3 del CP.

${ }^{66}$ Cfr. Mestre Delgado, E.: La Ley Penal, $N^{\circ}$ 100, Sección Editorial, LA LEY Enero-Febrero 20I3, Madrid

${ }^{67}$ Circular 4/1997, Fiscalía General del Estado sobre la extensión a terceros participes de los efectos de la regularización fiscal.
} 
fiscal el hecho de que este, de alguna forma, haya contribuido a la regularización, incluso a título de inductor.

- Si asesor fiscal se opone a la regularización, no le alcanzaran los efectos de la excusa absolutoria

- Si el asesor fiscal no colabora de ningún modo en la regularización, ni oponiéndose ni cooperando en ella, acorde con el criterio de la Fiscalía, el fiscal deberá valorar las circunstancias del caso aplicando al asesor fiscal o bien la excusa absolutoria o bien la atenuante recogida en el art. 2I.5 del $\mathrm{CP}^{68}$.

- Si el asesor fiscal intenta llevar a cabo la regularización, pero el contribuyente se opone, y al final dicha regularización no se practica, es claro que no podemos aplicar la excusa absolutoria a ninguno de los dos, ya que no se cumplen los presupuestos necesarios para ello. Ahora bien, si podremos aplicar el art. 2I.4 al asesor fiscal si este ha confesado a las autoridades la irregularidad (antes de que se inicien actuaciones por parte del Estado claro), o el art. 2I.5 que ya se ha visto anteriormente, si no procede a la confesión pero, sí que se observa que ha realizado conductas tendentes a conminar al deudor tributario a que regularice su situación.

- Por ultimo hemos de analizar si es necesario el pago de la cantidad defraudada para regularizar la situación. Hay que señalar que esta cuestión ha sido objeto de un amplísimo debate doctrinal, puesto que hay ciertos sectores de la doctrina entre los que se encuentra SÁNCHEZ PEDROCHE ${ }^{69}$, que postulan que no sería necesario el pago de la deuda, sino que bastaría con la presentación de la oportuna declaración complementaria, aunque esta no fuera seguida del correspondiente ingreso. Sin embargo, otra postura doctrinal y jurisprudencial concluye, basándose entre otras cosas en el significado semántico del término regularizar, que es necesario reparar el perjuicio causado, esto es no solo declarar, sino también pagar lo que falta por pagar. En tal sentido se ha pronunciado entre otras la STS Sala $2^{\mathrm{a}}$ I92/2006 de I-2-2006 (F.J.2 $\left.{ }^{\circ}\right)^{70}$

Yo me adhiero plenamente a la opinión sostenida por el TS y por la FGE en su Consulta 2/2009, sobre la interpretación del termino regularizar, en las excusas absolutorias previstas en los arts. 305.4 Y 307.3 del CP, puesto que, siguiendo a las citadas opiniones, me parece claro que regularizar implica arreglar el perjuicio causado a la Hacienda Pública, ya que, para empezar, lo que el tipo penal busca es reparar el daño causado a la Hacienda Pública, perjuicio que tiene como base la falta de pago y, sin la cual, no es posible reparación alguna y, por ende, la excusa absolutoria quedaría sin fundamento alguno.

Solo cuando nos halláramos ante la modalidad comisiva de la obtención de devoluciones indebidas, podría caber la excusa absolutoria con la mera presentación de la rectificación o declaración complementaria, siempre que esta se produjera antes de la

\footnotetext{
${ }^{68}$ «La de haber procedido el culpable a reparar el daño ocasionado a la víctima, o disminuir sus efectos, en cualquier momento del procedimiento y con anterioridad a la celebración del acto del juicio oral».

${ }^{69}$ Op. cit.I4. pág. 364.

${ }^{70}$ «Por lo tanto, según esta línea jurisprudencial, regularizar supone pagar, sin que baste la presentación de declaración complementaria. Por las mismas razones se estima ineficaz la regularización con ingreso parcial, sin perjuicio de que la reparación parcial del perjuicio pueda producir efectos en la determinación de la pena».
} 
obtención de las devoluciones, ya que en este caso el pago no se habría hecho por la AEAT y, por tanto, no habría que reparar este perjuicio patrimonial.

IV.7. Prescripción de la Responsabilidad Penal

Por último, es necesario saber cuándo prescribe la responsabilidad derivada de este delito.

Señalar que es un tema, polémico ya que la prescripción en el ámbito tributario, para que la Administración pueda exigir el pago de las deudas, ya sean liquidadas o autoliquidadas, y la prescripción de este delito, no coinciden ni remotamente, mas y todo a raíz de las últimas reformas legales.

La prescripción en el ámbito tributario nos la vamos a encontrar en el art. 66 de la LGT/2003, donde se establece la prescripción en un lapso temporal de 4 años; bien que con posibilidades de interrupción de la prescripción, como suele ser común en todas las ramas del ordenamiento jurídico español.

Ahora bien, a la hora de hablar del delito de defraudación tributaria tal cual se encuentra regulado en el CP, nos vamos a encontrar con que la prescripción, si concurren los presupuestos del art. 305 del CP será de 5 años. No obstante, si concurre alguna causa de agravación de las recogidas en el 305.bis.I, al ser la pena superior a 5 años, la prescripción del delito se amplía a ıo años, acorde con el art. I3I.I del CP.

Como resultado de esta dicotomía en los plazos prescriptivos en uno y otro ámbito, se han postulado dos teorías doctrinales y jurisprudenciales:

- Una parte de la doctrina considera que, prescrito en vía tributaria, carece de sentido que pueda seguir por la vía penal reclamando la deuda. Algunos de los argumentos esgrimidos por estos autores, entre los que se encuentran MARTÍn QUERALT ${ }^{71}$, SÁNCHEZ PEDROCHE ${ }^{72}$, se basan en el carácter de norma penal en blanco del art. 305 del CP; esta norma penal en blanco es la norma tributaria, si conforme a la norma tributaria, la responsabilidad prescribe porque ha pasado el plazo de 4 años y, además el tipo de objetivo del delito se basa en la existencia de una obligación tributaria, resultaría complejo que el Derecho Penal ignore esta prescripción tributaria que hace que esta obligación ya no exista. Además, se aduce que no hay bien jurídico protegido si consideramos que dicho bien tiene su fundamento en la recaudación tributaria. Si ya no hay nada que recaudar, mal vamos a castigar a una persona que ya no es deudora y que, de hecho, si ingresara la cantidad una vez operada la prescripción habría que considerarla un ingreso indebido. Asimismo, también cabe mencionar la tesis de la atipicidad de la conducta, ya que, siguiendo a PEDROCHE, «la prescripción de la obligación tributaria elimina la trascendencia jurídica del perjuicio producido, precisamente porque ya no es posible la elusión del pago». Esta corriente doctrinal se encuentra en consonancia, entre otras, con la SAP Madrid 404 /2000 de 6-II-2000 (F.J. $\left.3^{\mathrm{o}}\right)^{73}$.

\footnotetext{
${ }^{71}$ Cfr. Martin Queralt, J.: Rev. Tribuna Fiscal, No 22I, Sección La Opinión, CISS LA LEY, Marzo 2009, Valencia págs. 4 a 9 .

$7^{72}$ Cfr SÁncheZ-Pedroche, Op.cit.I4 págs. 379 y ss.

${ }^{73}$ «Así las cosas, el tema a discutir se contrae a determinar si la prescripción de la deuda en vía administrativa tiene o no incidencia sobre la tipicidad. La respuesta, a juicio de este Tribunal, ha de ser
} 
- La otra vertiente doctrinal nos postula que ambos plazos son independientes; si bien ello no es óbice para que, siguiendo la tesis de la STS I629/200I de Io -IO- 200I, bien que en su F.J. $2^{\circ}$ admite la independencia de ambos plazos prescriptivos, postula que si se rebasan los 4 años de prescripción tributaria no es posible la iniciación de proceso judicial alguno, no tenga relevancia la prescripción de la deuda tributaria. En tal sentido se ha manifestado entre otros MARTíNEZ GALINDO ${ }^{74}$.Esta corriente doctrinal se puede basar en que no estamos ante el mismo desvalor de la conducta en el ámbito penal que en el tributario, que el bien jurídico protegido consiste, no en una finalidad recaudatoria, sino en el cumplimiento de ciertos fines colectivos representados por la AEAT o, porque para que exista una excusa absolutoria en el orden penal, debe estar recogida expresamente en el CP y, en este caso, la prescripción tributaria claramente no lo está. En tal sentido, hay que decir que se ha manifestado buena parte de la jurisprudencia del TS como puede verse en la STS Sala $2^{\text {a }} 823 / 2013$ de 24-IO-20I3, F.J. 2 ${ }^{\text {o }}$ 75I/2003 de 28-II-2003 (F.J. 6 ${ }^{\circ}$ al I8), del que destacó por su rotundidad: «El plazo de prescripción del delito fiscal definido en el art 305 del Código Penal vigente (art. 349 del Código Penal anterior) es de cinco años, y no ha sido alterado por la entrada en vigor de la Ley I/98», STS Sala $2^{\circ}$ 44/2003 de 3-4-2003 (F.J. $4^{\circ}$ a I6), que rechaza la tesis de la atipicidad sobrevenida expresamente.

\section{Blanqueo de capitales}

\section{V.I. Caracterización y Evolución del Tipo}

Conviene, en primer lugar, analizar algunas cuestiones generales del delito de blanqueo de capitales.

Según MARTínEZ-BUJÁN ${ }^{75}$ podemos encontrar el antecedente del actual delito de blanqueo de capitales en la Ley de $1988^{76}$ que buscaba combatir el Tráfico Ilegal de Drogas y que, por ello, reformó el $\mathrm{CP} / \mathrm{i} 973^{77}$ introduciendo el art. 546 bis $\left.\mathrm{f}\right)^{78}$, que castiga las conductas de aprovechamiento y blanqueo del dinero procedente del tráfico de drogas.

Asimismo y, dado el indudable factor característico de internacionalidad inherente al delito de blanqueo de capitales, en el año ig88 se elaboró, en el marco de las Naciones Unidas, la Convención contra el Tráfico Ilícito de Estupefacientes y Sustancias Psicotrópicas que tipificaba como delito el banqueo de capitales provenientes de los distintos delitos derivados de las drogas ${ }^{79}$.

afirmativa, al entender que nos hallamos ante un supuesto de atipicidad sobrevenida, aunque efectivamente tal postura no es pacífica ni en la doctrina ni en la jurisprudencia».

${ }^{74}$ Martínez Galindo, G: «Especialidades de la prescripción en el delito fiscal» La Ley Penal, $\mathrm{n}^{\circ}$ 52, Sección Estudios LA LEY, Septiembre 2008, Madrid

75 Martínez-Bujan Pérez, c.: Derecho Penal Económico y de la Empresa Parte Especial, Tirant Lo Blanch $4^{\circ}$ Edición Valencia, Págs. 590 y ss.

${ }^{76}$ Ley Orgánica I/ı988, de 24 de marzo, de Reforma del Código Penal en materia de tráfico ilegal de drogas.

${ }^{77}$ Código Penal, texto refundido aprobado por Decreto 3096/1973, de I4 de septiembre

${ }^{78}$ Extracto del art.: «El que con conocimiento de la comisión de alguno de los delitos regulados en los artículos 344 a 344 bis b) de este Código recibiere, adquiriere o de cualquier otro modo se aprovechare para sí o para un tercero de los efectos o ganancias del mismo, será castigado con prisión menor y multa de un millón a I०० millones de pesetas».

${ }^{79}$ Vid por ejemplo arts. 3.I.b.i,3.b.I.ii de la Convención 
Esta convención fue ratificada por España en I990, lo cual modificó de nuevo la regulación vigente en nuestro país acerca de este delito.

Con la promulgación y entrada en vigor del $\mathrm{CP} / 1995^{80}$, nos encontramos con el art. 30I, que castiga el delito de Blanqueo de Capitales, indiferentemente de qué delito grave provenga el dinero.

Posteriormente, con la entrada en vigor de la Ley $15 / 2003^{8 \mathrm{I}}$, se eliminó el requisito de que el delito del cual procediera el dinero debía ser calificado como grave y, en $2010{ }^{82}$ se volvió a cambiar la redacción del precepto legal, ampliando de nuevo su ámbito de aplicación ${ }^{83}$.

Por último, hemos de realizar una mención al ámbito comunitario, en el cual se dicta en 2005 una Directiva para prevenir la utilización del sistema financiero para blanquear capitales o para financiar el terrorismo. Esta Directiva fue traspuesta por la Ley Io/20io de 29 de abril que, a su vez fue desarrollada por el RD 304/20I4 de 5 de mayo, ambos con una trascendencia capital a la hora de analizar las obligaciones y responsabilidades del asesor fiscal en esta materia ${ }^{{ }^{4}}$.

En cuanto a la jurisprudencia española, este delito ha sido bastante estudiado y analizado en todas sus redacciones. Buenos ejemplos de ello son las SSTS, Sala $2^{\mathrm{a}}$ 5/1993, de 2I-I-I993, I05I/2003 de I9-I2-2003, (F.J. Noveno-Decimotercero) ${ }^{85}$, Io67/2010 de 24-II2010 (F.J: ${ }^{\circ}$ ), y 487/20I4 de 9-6-20I4.

Asimismo, por su importancia mediática, merece destacarse el Auto de 25-6-20I4 del Juzgado de Instrucción de Palma de Mallorca $\mathrm{n}^{\mathrm{o}}{ }^{86}$ Antecedente de Hecho Octavo, (F.J. $8^{\circ}$ entre otros).

Para concluir esta parte, hemos de caracterizar el concepto de Blanqueo de Capitales y el bien jurídico protegido.

Podemos, siguiendo a MARTÍNEZ-BUjAN, definir el concepto de blanqueo de capitales, como «proceso de ocultación de bienes de origen delictivo con el fin de dotarlos de una apariencia final de legitimidad».

Sin embargo, en lo relativo al concepto de bien jurídico protegido por este delito, nos vamos a encontrar con una amplia polémica doctrinal, puesto que un sector doctrinal

\footnotetext{
${ }^{80}$ Ley Orgánica Io/I995, de 23 de noviembre, del Código Penal

${ }^{81}$ Ley Orgánica 15/2003, de 25 de noviembre, por la que se modifica la Ley Orgánica Io/1995, de 23 de noviembre, del Código Penal.

${ }^{82}$ Cfr. Alonso Carbajo, J. M.: «Evolución normativa del delito de blanqueo de capitales a tenor de su tratamiento en los ámbitos internacional, comunitario y nacional Fiscal de la Fiscalía Anticorrupción», Diario La Ley, $N^{o} 7736$, Sección Tribuna LA LEY, I5-II-20II, Madrid.

${ }^{83}$ Ley Orgánica 5/2010 de 22 de junio de 20I0, por la que se modifica la Ley Orgánica Io/1995, de 23 de noviembre, del CP.

${ }^{84}$ Op.cit., pág. 63

${ }^{85}$ Que dice (F.J. 9 ${ }^{\circ}$ : «Se ha dicho que el origen del movimiento legislativo en materia de blanqueo de capitales encuentra su raíz, fundamentalmente, en la lucha contra el tráfico de drogas, pero la Ley penal parte de una regulación general (conectado con un delito grave) e inserta un subtipo agravado para este origen, que es el más frecuente en la práctica».

${ }^{86}$ El muy conocido caso Noos, auto en el cual se mantiene la imputación de un muy conocido miembro de la Casa Real (pendiente de juicio).
} 
considera que busca proteger a la Administración de Justicia y otro que busca tutelar el orden socioeconómico.

En mi opinión, y siguiendo a MARTínEZ-BUJAN, ambas posturas tiene parte de razón ya que hemos de configurar este delito como un delito pluriofensivo ya que:

- Por un lado, si miramos donde se localizaba y, en palabras del autor, el precepto en el Preámbulo del Proyecto del CP de I992, así como de la Exposición de Motivos del citado Proyecto, parece claro que se configura como un delito de corte socioeconómico; máxime si pensamos que puede delimitarse el bien jurídico con la idea de proteger la licitud de los bienes que circulan en el mercado, de la introducción de aquellos bienes que tengan su origen en una actividad delictiva.

- Por otro lado, la gravedad de la pena hace suponer que no solamente nos hallamos ante una única lesión de un bien jurídico y, siguiendo al autor, parece que de la literalidad de la ley se desprende que el delito se orienta a la protección de la Administración de Justicia.

En lo que respecta al concurso del blanqueo de capitales con el delito de defraudación tributaria, siguiendo las dos líneas marcadas por las sentencias ya estudiadas en epígrafes anteriores ${ }^{87}$ podemos diferenciar dos posiciones:

- Acorde con la tesis postulada en la Sentencia del caso Nécora, anteriormente citada, así como la del Caso Roldán, podríamos considerar al asesor fiscal cómplice, por ejemplo, de un delito de blanqueo de dinero proveniente de una estafa y, además, colaborador necesario en un delito de defraudación tributaria, pues ha realizado autoliquidaciones negativas para que su cliente obtenga devoluciones, obviando su enorme patrimonio proveniente del delito. Ahora bien, también nos vamos a encontrar con bastante polémica doctrinal al preguntarnos si el delito de defraudación tributaria puede ser el delito antecedente a un delito de blanqueo de capitales, en síntesis se trata de blanquear los beneficios obtenidos mediante un delito de defraudación tributaria. Siguiendo la Sentencia del caso Ballena Blanca ${ }^{88}$ en su F.J. 37, una postura doctrinal sostiene que dicho delito si puede ser antecedente del delito de blanqueo de capitales, teniendo en cuenta que si lo puede ser, las ganancias obtenidas por el tráfico de drogas (ambos son delitos con trascendencia patrimonial y algunas similitudes conceptuales) y, no debemos confundir el blanqueo de los fondos que dan lugar a la cuota defraudada con el blanqueo de los fondos de la cuota defraudada. Además la Sala se inclina a sostener esta postura por las siguientes razones:

- En el delito de defraudación tributaria el objeto del delito son los rendimientos que dan lugar a la cuota tributaria, en el delito de blanqueo de capitales el objeto lo conforma la ganancia que se deriva del delito fiscal, o sea, la cuota defraudada

- Como hemos visto en anteriores epígrafes, los bienes jurídicos son distintos en uno y otro delito

- Acorde con la Ley Iо/20Iо, art. I.3, se postula expresamente que serán bienes procedentes de una actividad delictiva a efectos del blanqueo de capitales, entre otros, la

\footnotetext{
${ }^{87}$ Vid Epígrafe Introducción a la responsabilidad penal del asesor fiscal

${ }^{88}$ STS Sala $2^{\circ} n^{\circ} 974 / 2012$ de 5-I2-20I2
} 
cuota defraudada a Hacienda. ${ }^{89}$ Además el Código Penal en su art. 30I.I habla de actividad delictiva como presupuesto antecedente para el delito de blanqueo, actividad delictiva como es el delito de defraudación tributaria

- Esta parece ser la postura que adopta la Directiva de la Unión Europea 2015/849 en su artículo 3.4, que aún no ha sido traspuesta a nuestro ordenamiento.

- Además y siguiendo a la Sentencia, el CGPJ se mostró proclive a que la cuota tributaria defraudada (siempre que constituyera delito) sirviera como antecedente para el delito de blanqueo de capitales..$^{\circ}$

- Por último y siguiendo a la Sentencia estudiada, esta posibilidad se contempla en Francia, Alemania o Bélgica.

- Otra postura doctrinal, sostenida por la Sentencia del Caso Urralburru entre otras $^{91}$, postula que las ganancias que tienen un origen directo en un delito, no pueden dar lugar a un delito posterior de defraudación tributaria, pues sería absorbido por el delito precedente si estos ingresos proceden de un modo directo de este delito, este delito precedente ha sido objeto de condena y en la condena se haya incluido el comiso de las ganancias obtenidas o se haya condenado a devolverlas en concepto de responsabilidad civil. Asimismo, y en lo que respecta a la posibilidad de que el delito de defraudación tributaria sea un delito precedente del de blanqueo de capitales, una parte doctrinal considera que no puede, ya que estaríamos vulnerando el principio non bis in ídem, puesto que en el tipo de injusto del delito de defraudación tributaria se incardina la obtención de esta cuota tributaria, y ya se está suponiendo que va a ser utilizada como convenga al autor. Además, el delito de defraudación tributaria no originaria los fondos objeto del delito, ya que ya existían en el patrimonio antes de la defraudación tributaria y siguen existiendo después sin que se originen por dicha defraudación, como postula la Sentencia Ballena Blanca ${ }^{92}$

\section{V.2. Obligaciones para el Asesor Fiscal derivadas de la Normativa de Prevención del Blanqueo de Capitales}

A la hora de abarcar el conjunto de obligaciones que se derivan para el asesor fiscal de la normativa de prevención del blanqueo de capitales, (los problemas relativos al secreto

\footnotetext{
${ }^{89}$ Ley iо/2010 de 28 de abril, de prevención del blanqueo de capitales y financiación del terrorismo, art. I.2, que dice: «A los efectos de esta Ley se entenderá por bienes procedentes de una actividad delictiva todo tipo de activos cuya adquisición o posesión tenga su origen en un delito, tanto materiales como inmateriales, muebles o inmuebles, tangibles o intangibles, así como los documentos o instrumentos jurídicos con independencia de su forma, incluidas la electrónica o la digital, que acrediten la propiedad de dichos activos o un derecho sobre los mismos, con inclusión de la cuota defraudada en el caso de los delitos contra la Hacienda Pública».

$9^{\circ}$ Informe del CGPJ sobre el Anteproyecto de Ley Io/2010 de prevención del blanqueo de capitales y financiación del terrorismo, realizado en 2009 que en su pág. 63 postula: «En principio, la cuota defraudada la Hacienda Pública en cuanto sea el producto de un delito fiscal, podría ser objeto de una operación de blanqueo de capitales».

${ }^{1}$ Vid entre otras SSTS $\mathrm{n}^{\circ}$ III3/2005 de I5-9-2005 F.J. IO ${ }^{\circ}, 769 / 2008$ de 30-IO-2008 FJ $4^{\circ}, 5^{\circ}$ y6 $^{\circ}$, 906/2009 de 23-9-2009 F.J. I

$9^{2}$ Op.cit. 89. FJ.37: «No es posible imputar la ganancia a la omisión (ilícita) cuando natural u antológicamente puede hacerse a una acción lícita. Por eso, si la ganancia tiene por causa un hacer positivo licito, no cabe considerarla de origen ilícito por el hecho de que el autor haya omitido típicamente una acción que hubiera mermado la ganancia. La ganancia de una actividad lícita no deviene en ilícita por la sola circunstancia de que no se tribute por ello, ni siquiera porque se oculte con el fin de evitar el pago de un tributo».
} 
profesional los analizaremos en el epígrafe siguiente) resulta obligado acudir en primer lugar a la Ley Iо/20Io de 29 de abril y, posteriormente al Reglamento 304/20I4 de 5 de mayo que, como nos postula su Disposición Final Tercera (e.v. el 5/05/2014 salvo algún aspecto del art. 4.I. ${ }^{93}$.

Antes de iniciar el estudio de estas obligaciones, destacaré las obligaciones de información, entre la que destaca la información al SEPBLAC, será tratada en el epígrafe siguiente, relativo al deber de confidencialidad, ya que me parece que ambos extremos están muy relacionados.

Acorde con la Ley io/20Io el asesor fiscal (externos ya que estas obligaciones impuestas por la Ley acorde a su art. 2.I, letra $\mathrm{m}$ ) parece que recaen sobre los asesores fiscales cuando estos presten sus servicios a terceros que les contraten ${ }^{94}$ ) tienen, entre otras, estas obligaciones ${ }^{95}$ :

- Identificación de las personas que intervienen en las operaciones mediante los correspondientes documentos (También llamada identificación formal)

- Tratar de implementar las medidas que se consideren oportunas para determinar la estructura de propiedad o de control de las personas jurídicas que contraten con ellos: Bastante complejo para el asesor fiscal, debido a que, para ello, haría falta que el cliente les suministrara no solo los datos económicos, sino la práctica totalidad de los datos organizativos, técnicos y de producción de su empresa..$^{96}$

- Discernir si sus clientes actúan en nombre de terceros y, si es así, averiguar quién es el tercero

- Obtener información sobre la naturaleza y el fin del negocio que sus clientes quieren desarrollar, además el asesor fiscal también debe conocer la naturaleza de la actividad empresarial del cliente y debe adoptar medidas para comprobar que la información que le suministran es veraz

- Deben efectuar un seguimiento continuo de la relación de negocios que mantengan con el cliente, realizando un escrutinio de las operaciones que se desarrollen durante la misma

Asimismo se establece que el asesor fiscal pueda aplicar en mayor o menor grado todas estas obligaciones ${ }^{97}$ (salvo las denominadas de identificación formal que no admiten graduación de aplicación alguna) dependiendo del riesgo del cliente o de la operación, estableciéndose además que el grado de aplicación deberá recogerse en la política de admisión de clientes. Por último, también el al artículo 7 se establece que de no poder

\footnotetext{
${ }^{93}$ Vid Art. 4.I Reglamento 304/20I4 de 5 de mayo op cit., pág. 50.

${ }^{94}$ Acorde con Aliaga MÉndez, J. A.: Normativa Comentada de prevención del blanqueo de capitales. La Ley, Madrid 20Io. Artículo 2 Sujetos Obligados, doctrina que forma parte del libro Normativa Comentada de prevención del blanqueo de capitales, LA LEY, Madrid-20Io págs. 80 y ss.

${ }^{95}$ BARRAChina JuAn, E.: Obligaciones para el asesor fiscal impuestas por la nueva Ley de Blanqueo de Capitales http://www.aranzadi.es/blanqueodecapitales/pdf/2.RECOMENDACIONESPROFESIONALES_papel-nss.pdf

${ }^{6} \mathrm{Y}$ aun así si no son capaces de determinarla la ley en su art. 4.4 tienen que abstenerse de realizar actuaciones negociales con ellos.

${ }^{97}$ También llamadas medidas de diligencia debida ex art 7 Ley Io/20ı
} 
aplicarse estas medidas de diligencia debida, se exige que el asesor no inicie relación negocial con los clientes afectados o, caso de haberla iniciado ya, no ejecute las operaciones sospechosas. Esta enumeración de obligaciones se ve matizada por la inclusión de las medidas de diligencia debida simplificada ${ }^{98}$ y las medidas de diligencia debida reforzada ${ }^{99}$. Destacar que, como ha postulado la jurisprudencia ${ }^{\text {ioo }}$, las medidas de diligencia debida simplificada pueden darse con productos o con clientes y, al igual que ocurre en las medidas de diligencia reforzada, realiza una remisión al Reglamento de 20I4, si bien en el caso de las medidas de diligencia debida la remisión es más amplia. Las medidas de diligencia reforzada se distinguen del resto porque han de utilizarse cuando nos encontremos con un riesgo elevado de blanqueo de capitales y de financiación del terrorismo $^{\text {Ior }}$

En lo que respecta a las concretas medidas de diligencia debida simplificada, así como a los supuestos concretos de aplicación, establecidos por el Reglamento de 2014 que desarrolla esta ley (y sin ánimo de ser exhaustivos) podríamos decir que el Reglamento nos postula en sus arts. I5 y i6 que se aplicarán, entre otros supuestos, desde el punto de vista subjetivo a clientes participados de algún modo por Administraciones Públicas, a bancos o a sus sucursales, que tengan su domicilio en la UE, o a sociedades cotizadas de ámbito europeo $^{\text {102 }}, y$, desde el punto de vista objetivo, a pólizas de seguro cuya prima anual no exceda de I.000 euros ( o una prima única no superior a 2500,00), planes de pensiones y otros sistemas de previsión social recogidos en el art. 5I de la Ley del IRPF ${ }^{103}$, entre otros supuestos.

Asimismo, y acorde con el art. I7, entre otras medidas de diligencia debida simplificada, estaría reducir la periodicidad de los procesos de revisión documental y, por ejemplo, no recabar la información de la actividad profesional del cliente, sino que bastaría con inferirlo por el tipo de operación que se desarrolle.

En lo que respecta a las medidas de diligencia debida reforzadas, se aplicarán, entre otros supuestos, cuando nos encontremos ante operaciones con banca privada o, lógicamente, cuando nos encontremos ante una operación comercial con un paraíso fiscal. Asimismo el art. I9.3 del Reglamento nos postula una serie de características, ya sean del cliente o de la operación, que hace necesario calificarla como de alto riesgo, entre las que merece destacarse el hecho de ser un cliente no residente en España, una sociedad de mera tenencia de activos, o encontrarnos ante una relación de negocio ejecutada por un intermediario. En general y de acuerdo con el artículo 20 del Reglamento, las medidas de diligencia debida reforzada suelen consistir en la obtención de información adicional sobre

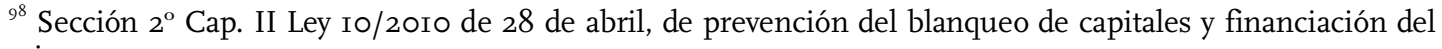
terrorismo

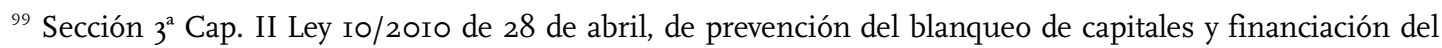
terrorismo

${ }^{100}$ SAP Vizcaya $n^{\circ} 726 / 2013$, Sección 4 a , 20-12-2013

${ }^{10} \mathrm{~A}$ modo de ejemplo la Ley recoge alguno de estos supuestos de riesgo como ocurre con operaciones de negocio no presenciales efectuadas a través de medios telemáticos o relaciones/ operaciones negiociales con personas que tengan responsabilidades públicas.

${ }^{102}$ Cfr. Aparicio DíAz, L.: «Notas sobre el nuevo Reglamento de la Ley de Prevención de Blanqueo de Capitales y de la financiación del terrorismo», Diario La Ley, $N^{o}$ 8337, Sección Tribuna, LA LEY 20-6-20I4, Sevilla.

${ }^{103}$ Op.cit., pág. I2
} 
diferentes aspectos como el propósito del negocio, los fondos, o el origen del patrimonio del cliente, sin embargo también se recoge la posibilidad de establecer medidas que restrinjan la cuantía de las operaciones o los medios de pago empleados o, incluso, exigir que los pagos se realicen en una cuenta a nombre del cliente en un banco domiciliado en la UE (o en algunos países terceros) o antes de realizar la operación recabar autorización del SEPBLAC.

\section{V.3. Obligaciones de Información y Deber de Confidencialidad}

Tanto el Reglamento como la Ley, se basan en la obtención de información con carácter previo a la operación, para tratar de prevenir el hipotético blanqueo de capitales o una financiación de células terroristas. Destacar que, como recoge el Dictamen del Consejo de Estado acerca del Reglamento ${ }^{\text {104 }}$, el Reglamento pretende recoger un conjunto de recomendaciones del Grupo de Acción Financiera Internacional publicadas en 2012 y que versan sobre la financiación del terrorismo y el lavado de dinero ${ }^{\text {ros }}$, que en su página I4 nos señalan, por ejemplo, medidas de identificación de sujetos.

En la Ley ıо/20Io, la obligación de información la observamos en el arts. I8, 20,21 y 24 entre otros que establecen la obligación de comunicación por parte de los sujetos obligados al SEPBLAC de toda operación en la que existan indicios de blanqueo de capitales, identificando a los intervinientes de la misma, aportando datos acerca de la operación, exposición de todas las circunstancias que se consideren relevantes acerca del posible blanqueo de capitales de la operación etc... Además, el art. 20 nos establece una obligación de comunicación sistemática al SEPBLAC por parte de los sujetos obligados, comunicaciones que, acorde con el art. 27 del Reglamento, será mensual en ciertos casos como operaciones con dinero físico o cheques con una cuantía superior a 30.000 euros, operaciones con paraísos fiscales $u$ otras operaciones que se determinen por Orden del Ministerio de Hacienda y Competitividad. ${ }^{\text {106 }}$

Sin entrar a estudiar en este apartado las sanciones administrativas por el incumplimiento de estas obligaciones (aunque en las sentencias de la nota al pie 90 si se analizan) hay que analizarlas desde el prisma del asesor fiscal y el deber de confidencialidad. A este respecto resulta imprescindible diferenciar 2 posibles situaciones:

- El asesor fiscal es a la vez abogado de su cliente

- El asesor fiscal no es abogado sino otro profesional que carece de una obligación especifica de secreto en el desarrollo de su profesión.

Vamos a analizar en primer lugar la situación que se da cuando el asesor fiscal es a su vez abogado del cliente. Lo primero que hay que decir es que el Secreto Profesional del abogado se encuadra en el art. 24.2 de la CE, en el art. 43 del Estatuto General de la

${ }^{104}$ Dict. del Consejo de Estado al Proyecto de Real Decreto por el que se aprueba el Reglamento de la Ley ı०/20Iо, de 28 de abril, de prevención del blanqueo de capitales y de la financiación del terrorismo aprobado el 24/4/20I4, núm. de exp. 393/20I4 (Ministerio de Economía y Competitividad).

${ }^{105}$ Vid International Standars on Combating Money Laundering and the Financing of Terrorism and proliferation, The FATF recommendations, February 20I2 http://www.fatfgafi.org/media/fatf/documents/recommendations/pdfs/FATF_Recommendations.pdf

${ }^{106}$ Como ejemplo de estas obligaciones entre otra la STS, Sala $3^{\circ}$, de I7-IO-20I4, Rec. 472/20I3 F.J. $2^{\circ}$. 
Abogacía $^{\mathrm{ro7}}$, en el art. 542.3 de la LOPJ ${ }^{\mathrm{108}}$ o también lo podemos encontrar recogido en el art. 22 de la Ley Iо/20Iо anteriormente citada.

Sin embargo, la existencia del Secreto Profesional del Abogado no quiere decir que el Secreto Profesional se configure como un derecho absoluto que no puede decaer ante nada, ni quiere decir que no tenga límites, de hecho la jurisprudencia constitucional ha postulado que ni vulnera el secreto profesional la comunicación a la AEAT del nombre del cliente, ni de las cantidades pagadas por este en concepto de honorarios o las certificaciones de los movimientos de cuentas bancarias ${ }^{\text {109. }}$.

Dicho lo cual, hemos de observar que en el citado art. 22 de la Ley 10/2010 ya configura una excepción a los deberes de información en el caso de abogados cuando actúen o bien representando al cliente en procesos judiciales (inclusive cuando asesoran sobre cómo evitar un proceso) o bien determinando la posición jurídica del cliente. Sin embargo es opinión doctrinal ${ }^{\text {II }}$ que no están determinando la posición jurídica del cliente ( y por tanto no se encontrarían amparados por el secreto profesional), cuando asesoran previamente a la realización de una operación acerca de cómo realizarla, pues en este supuesto se está determinando la manera de realizar la operación y se está incidiendo en su desarrollo, sin embargo cuando la operación ya se haya desarrollado, y el cliente le pregunte a su abogado asesor acerca de las consecuencias jurídicas que ha tenido la misma, así como de sus posibilidades de actuación, si estaríamos protegidos por el Secreto Profesional. Se ha planteado doctrinalmente el hecho de que, si bien los asesores fiscales en principio se configuran como obligados plenos en cuanto a las labores de información, los abogados tienen estas vías de excepción a la aplicación de las obligaciones de información, y por tanto hay que discernir que sucede cuando el abogado es a su vez asesor fiscal. En nuestra opinión, y siguiendo entre otros al autor anterior ${ }^{\mathrm{III}}$, se aplicará lo anteriormente expuesto, primando en los supuestos protegidos para el abogado por el Secreto Profesional, la condición de Abogado respecto de la de Asesor Fiscal ( ya que de lo contrario supondría una limitación excesiva del Secreto Profesional que podría, incluso, devenir inconstitucional).

Merece señalarse, por último, y referido al ámbito de la asesoría por parte de abogados, el tema relativo a los abogados internos de una empresa, puesto que aquí se ha venido considerando que no les alcanza el secreto profesional en lo que respecta a sus comunicaciones internas con la empresa ${ }^{\text {II2 }}$, como ha sido postulado por la jurisprudencia comunitaria $^{\mathrm{II3}}$.

\footnotetext{
${ }^{107}$ RD 658/200I, de 22 de junio, por el que se aprueba el Estatuto General de la Abogacía Española.

${ }^{108}$ «Los abogados deberán guardar secreto de todos los hechos o noticias de que conozcan por razón de cualquiera de las modalidades de su actuación profesional, no pudiendo ser obligados a declarar sobre los mismos».

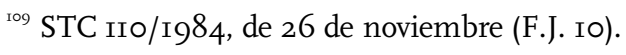

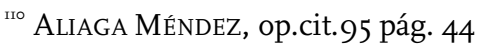

"II O a CABEZUela SANCho, D. El secreto profesional de los abogados y el blanqueo de capitales, Diario Juridico Sección de Opinión I2 de marzo de 2012 Madrid.

${ }^{\text {I2 } 2}$ AleiX Fuertes-PlanAs, C.: «Evolución del secreto profesional de los abogados» Diario La Ley, $N^{o} 8_{3} 62$, Sección Doctrina, 25 de Julio de 2014, Madrid LA LEY.

${ }^{\text {Ir3 }}$ STJ (Gran Sala) de I4-9-20ıо, caso Akzo Nobel Chemicals Ltd. y otros, C-550/07 P Punto 40 a 5 I.
} 
Si nos encontramos, por el contrario ante un asesor fiscal que no sea abogado de su cliente (o que no tenga un deber de secreto profesional en el ejercicio ordinario de la profesión), parece que no estará amparado por el art. $22 \mathrm{y}$, por tanto se caracterizan como obligados plenos a la totalidad de las obligaciones de información establecidas por la Ley ıо/20ıо. Ello no deja de resultar sorprendente si observamos que ni la Directiva 2005/60/CE ${ }^{\mathrm{II} 4}$ ni la Directiva 2006/70/CE ${ }^{\mathrm{II}}$ (las directivas que traspone la Ley 10/2010) recogen una exigencia de información similar para el asesor fiscal, de hecho la Directiva 2005/60/CE permite conforme a su art. 23.2 que se extienda las características de la no sujeción a deberes de información para abogados por el secreto profesional a los asesores fiscales y, de hecho la ley antecedente a la Ley го/2010 ${ }^{\mathrm{II} 6}$ recogía expresamente en su artículo 3.4 la extensión a los asesores fiscales ,que cumplieran los requisitos vistos antes para aplicar el secreto profesional a los abogados, de la excepción de los deberes de información debido al secreto profesional, de tal manera que caemos en la paradoja de que hasta 2010 el secreto profesional amparaba a este tipo de asesor fiscal conforme a la Ley I9/I993 pero desde la entrada en vigor de la Ley IO/20IO ( a partir del 3I-4-20IO) son sujetos obligados plenos no amparados por el secreto profesional ${ }^{\text {II7 }}$.

Hay que tener en cuenta que la nueva Directiva 849/2015, establece en su artículo 34.2, una exención a los Asesores Fiscales por razón del secreto profesional. ${ }^{\mathrm{II}}$

\section{Conclusiones}

Lo primero que he de decir es que en este trabajo, dada la limitación obligatoria en extensión, no se ha pretendido hacer un análisis global y exhaustivo de las responsabilidades dimanantes del ejercicio de la asesoría fiscal, debido al hecho indubitado de que, en el ejercicio de la asesoría fiscal inciden no solo prácticamente todas las ramas del ordenamiento jurídico, sino también estudios de carácter económico y sociológico, además de estudios acerca de la Ética Fiscal, la Ética del Asesor Fiscal y la propia Ética del contribuyente $^{\text {rig. }}$. Nuestras conclusiones serian:

${ }^{114}$ Directiva 2005/60/CE Del Parlamento Europeo y del Consejo de 26-I0-2005 relativa a la prevención de la utilización del sistema financiero para el blanqueo de capitales y para la financiación del terrorismo

"Is Directiva 2006/70/CE de la Comisión de I-8-2006, por la que se establecen disposiciones de aplicación de la Directiva 2005/60/CE del Parlamento Europeo y del Consejo en lo relativo a la definición de «personas del medio político» y los criterios técnicos aplicables en los procedimientos simplificados de diligencia debida con respecto al cliente así como en lo que atañe a la exención por razones de actividad financiera ocasional o muy limitada

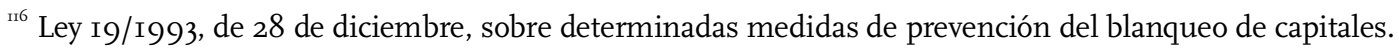

${ }^{\text {rr7 }}$ Portal del Consejo General de Economistas Secreto Profesional

http://rasi.economistas.es/consultascn/secreto-profesional/

п8 «Los Estados miembros eximirán de las obligaciones establecidas en el artículo 33, apartado I, a los notarios, otros profesionales independientes del Derecho, los auditores, los contables externos y los asesores fiscales única y exclusivamente en aquellos casos en que tal exención se refiera a la información que estos reciban de uno de sus clientes u obtengan sobre él durante la determinación de la posición jurídica de su cliente o el ejercicio de sus funciones de defensa o representación de dicho cliente en un procedimiento judicial o en relación con dicho procedimiento, incluido el asesoramiento sobre la incoación de un procedimiento judicial o la forma de evitarlo, independientemente de si han recibido u obtenido dicha información antes, durante o después de tal procedimiento».

${ }^{\text {in }}$ Álvarez García, S. Y Herrera Molina, P.M.: Ética Fiscal Documento nº/2004 Instituto de Estudios Fiscales Madrid págs. 77 y ss. 
- Nos enfrentamos a una figura que, en la actualidad, carece de una regulación legal, si bien es cierto que en los últimos años se han ido sucediendo distintas autorregulaciones procedentes en gran medida de los Colegios Profesionales que tratan, no solo de dotar de un Código Deontológico al Asesor Fiscal, sino de enunciar reglas para el desarrollo de su profesión. Esta carencia de regulación viene originada por el hecho de que la figura del asesor fiscal es relativamente novedosa en nuestro ordenamiento jurídico. Sin embargo, y dada la gran complejidad del ordenamiento tributario y en aras de una mejor seguridad jurídica para el contribuyente, resulta indiscutible que la figura se ha hecho imprescindible, no solo para buena parte de las empresas, sino también para numerosos particulares. Por ello, mi primera propuesta de mejora consistiría en dotar al asesor fiscal de una definición parecida a la del Borrador del Proyecto de Ley de Regulación del Gestor Tributario, lo que conlleva también la exigencia de unos requisitos mínimos, que deberían consistir en la necesidad de ser Graduado en Derecho, en Administración de Empresas o Economía, superación de un curso específico de habilitación de, por lo menos 2 años de duración e inscripción obligatoria en el Registro de Asesores Fiscales.

- Vemos que el sector de la asesoría fiscal es un sector muy atomizado, con un gran número de participantes en el mercado, pero de bajo tamaño, predominando el autoempleo, y que no está creciendo parejo al crecimiento de la complejidad tributaria.

- En lo que respecta a la responsabilidad tributaria del Asesor Fiscal hemos de mencionar, que se configura como solidaria si ha colaborado activamente en la infracción tributaria o la ha causado, responsabilidad que englobará la deuda tributaria y la sanción (aunque esto último como se ha dicho anteriormente, es polémico por el principio de personalidad de la pena entre otras cosas). La segunda propuesta de mejora en este ámbito sería la introducción de categorías de participación en la norma tributaria, a semejanza de lo que ocurre en el Derecho Penal, la supresión, en algunos casos, del derecho de repetición dimanante de la responsabilidad solidaria, una mayor claridad y concreción en lo que se refiere al dolo, culpa y posibles errores del asesor fiscal.

- En lo que respecta a la responsabilidad penal, la mayoría de la doctrina y de la jurisprudencia lo definen como un delito especial, propio de infracción del deber, por tanto el asesor fiscal solo puede ser participe y nunca autor, sin embargo una parte de esta doctrina ( a la cual me adhiero) considera que, si bien la modalidad activa del tipo consistente en la falta de ingreso es un delito especial propio, la modalidad de obtención de devoluciones indebidas es un delito común y, por tanto en esta modalidad el asesor fiscal puede ser autor. Asimismo, y a raíz de los pronunciamientos del TC, se ha considerado que el Fraude de Ley Tributario no es sancionable penalmente. Sin embargo merecen destacarse las disensiones doctrinales acerca de la llamada excusa absolutoria, aunque ahora parece que la jurisprudencia y la doctrina se inclinan por configurarla como un elemento negativo del tipo, así como introducir el requisito de pago para la regularización, merece ser destacada, de una manera muy positiva, la Circular de la Fiscalía del Estado que aclara los efectos de la misma en las distintas actuaciones que pueden ser llevadas a cabo por el asesor fiscal. No obstante a ello, siguen existiendo graves problemas para conciliar la prescripción tributaria con la prescripción penal, que deberían ser resueltos a nivel legislativo de manera urgente ya que, de lo contrario, estamos conculcando gravemente la seguridad jurídica, máxime cuando la pena puede llegar a los io años. 
- Por último, y en lo que respecta al Blanqueo de Capitales, nos hallamos con una materia en claro desarrollo. Ello hace que haya lagunas y problemas jurídicos que han de ser solventados a la mayor brevedad posible. Debe, en mi opinión, tratar de buscar un equilibrio entre la prevención del blanqueo de capitales (y de la financiación del terrorismo) y la figura y características que resultan definitorias del ejercicio de la profesión de asesor fiscal. No es adecuado pretender que el asesor fiscal se convierta en un policía o un investigador de la Administración Tributaria, ello conculcaría el mismo fundamento de la figura, que no es otro que el asesoramiento al cliente en temas fiscales defendiendo sus intereses, no los de la Administración. En este tema también ha de reconocerse, el secreto profesional del asesor fiscal en los mismos términos que se le reconoce al abogado asesor fiscal, por la mera razón de que, en esos términos, las actuaciones de uno y otro van a ser muy similares y no veo fundamento a este tipo de discriminaciones arbitrarias.

Para finalizar este Trabajo de Fin de Grado en Derecho permítanme citar la siguiente frase del economista y pensador francés del siglo XIX, F. BASTIAT:

«La gente ya está empezando a darse cuenta de que el Estado es demasiado costoso. Lo que aún no terminan de comprender es que el peso de ese costo recae sobre ellos». 